\title{
Global finite-frequency S-wave delay-times: how much crust
}

\section{matters}

\author{
Frédéric Dubois ${ }^{\star}$, Sophie Lambotte, Christophe Zaroli, Luis Rivera
}

Institut de Physique du Globe de Strasbourg, UMR 7516, Université de Strasbourg, EOST/CNRS, F-67084 Strasbourg cedex, Fran

\section{SUMMARY}

We investigate the influence of crust on time residual measurements made by crosscorrelation in the $10-51 \mathrm{~s}$ filtering period range on a global scale, considering two crustal models: CRUST2.0 and CRUST1.0. This study highlights, in a quantitative way, crustrelated time corrections. One part of this correction is directly linked to the body wave travel time through the crust as predicted by the ray theory, whereas a second part is related to interferences with multiple crustal reflections. This second component, called finite-frequency crustal correction, is frequency-dependent unlike the ray-theory based correction. We show that if this frequency-dependent crust-related correction is not taken into account in cross-correlation measurements, it may lead to a dispersive effect in Swave delay-times that could ultimately bias tomographic models. On average, this finitefrequency correction increases with the filtering period. Comparisons between the two crustal models highlight the significant dispersive effect of the crust, which has complex patterns depending on geological contexts, with an important role of the sediment thickness. Although ray crustal corrections remain important, finite-frequency crustal effects may lead to a bias in measurements if not properly taken into account; on average they may reach $0.9-1.6 \mathrm{~s}$ for CRUST2.0 and $0.5-1.6 \mathrm{~s}$ for CRUST1.0, for period ranging from $10-51 \mathrm{~s}$, respectively. 
Key words: body waves - wave propagation - crustal structure - seismic tomography

\section{INTRODUCTION}

Body-wave seismic tomography allows to detect seismic heterogeneities into the Earth's interior induced by potential thermal and/or chemical anomalies. For several years, body-wave measurement methods in seismology have evolved from first-onset picking to time residual estimation by cross-correlation techniques. Cross-correlation operator estimates the similiarity between two different waveforms, such as between a synthetic seismogram and an observed one at different time-lags. Now the cross-correlation is widely used to estimate the time-shift between two waveforms in raytheory (RT) (e.g., Ritsema et al. 2011) as well as in finite-frequency (FF) tomography (e.g., Sigloch \& Nolet 2006; Nolet et al. 2008; Hosseini \& Sigloch 2015; Zaroli et al. 2015; Kolstrup \& Maupin 2015), in particular for its robustness. The improvement brought by cross-correlation in travel-time measurements allows to investigate Earth's structure more accurately (e.g., Woodward \& Masters 1991a,b; Masters et al. 1996; Montelli et al. 2004; Hung et al. 2004; Montelli et al. 2006; Yang et al. 2006; Zaroli et al. 2015) and to refine hypocenter location for earthquakes (e.g., Shearer 1997; Schaff et al. 2001). Cross-correlation measurements give much better results than picking, especially for S-waves which are often faded by P-waves coda (e.g., Schaff \& Waldhauser 2005).

In global mantle tomography we aim at imaging elastic heterogeneities in the mantle. Therefore, we would like to get rid of crustal signals since the crust is probably the most heterogeneous region of the Earth. Besides all seismic waves have to travel through the crust at least once before being recorded at a seismic station. Consequently the crust may have a significant influence on all travel-time measurements (Bolton \& Masters 2001; Nolet et al. 2008). The crustal structure may be known from local studies such as surface wave tomographies or seismic surveys. It is therefore possible to apply crustal corrections to travel time measurements (Nolet et al. 2008). Another way to overcome the problem of crustal influence is to work with differential traveltimes measurements Pdiff-PKP (e.g., Kárason $\&$ Hilst 2001). They may be used to reduce the sensitivity around the source and receiver locations. When a seismic phase crosses the crust, reflections and conversions occur at the interfaces of the different crustal layers. These reflected/converted phases will reach the seismometer just after the main phase and may arrive close enough to be included in the time window used for the cross-correlation. Hence, all seismic waves experience waveform distortions produced by crustal reverberations. These interferences between crustal phases and the target seismic phase depend on the crustal structure and the dominant period used to filter seismograms (e.g., Ritsema et al. 2009). To our knowledge, a few

* email: fredericdubois@unistra.fr 
previous studies have investigated these crustal effects on "broad-band" filtered seismic waveforms (usually the 2-50 s period range for S-waves) (e.g., Fukao et al. 2003; Obayashi et al. 2004; Yang \& Shen 2006; Ritsema et al. 2009; Kolstrup \& Maupin 2015; Obayashi et al. 2017). Moreover, some of them investigated crustal reverberations in specific geological contexts, like oceanic domain (Yang \& Shen 2006; Obayashi et al. 2017), or South Scandinavia (Kolstrup \& Maupin 2015), what may limit the assessment of crustal reverberations, and their effect on seismic data for other geological settings.

In the context of multiple-frequency seismic tomography, time residuals measured at different periods correspond to different sampling of the Earth's interior and they are expected to better constrain multi-scale seismic heterogeneities. We aim at investigating narrow-band filtered seismic waveforms to assess the crustal contribution at different frequencies. Our goal is to show how much crust matters in cross-correlation S-wave time residuals on a global scale, including different geological settings.

The full shape of a seismic phase matters when measuring by cross-correlation (Dahlen et al. 2000). Therefore, it is essential to properly model crustal phases (CP) in seismograms in order to have an adequate frequency-dependent crustal time residual corrections (e.g., Ritsema et al. 2009; Zaroli et al. 2010; Kolstrup \& Maupin 2015). Otherwise one could interpret finite-frequency crustal signals as mantle-structure related anomalies . Off course, the ray-theory based correction must still be applied, but an additionnal correction is needed to take into account the variable sensitivity of finite-frequency body waves to the crust. Crustal reverberations are of first importance at low frequencies (Obayashi et al. 2004), and their influence increase with period. However, even when measuring travel-times by cross-correlation for RT tomography purposes, one has to take into account these crustal effects as well. Indeed, crustal phases can distort the waveform and thus ultimately impact the measured time residuals.

Since we are going to quantitatively evaluate the impact of crustal effects on teleseismic time residuals, one needs a crustal model. In an ideal world, we could find a good description of the geology and geotechnical features of the soil below all stations. But this cannot be systematically done due to economic or technical reasons. Off course, if an accurate crustal model under each station is available, one should used it to simulate crustal influence in synthetics. But in our global context we have to choose a 'not-too-bad' crustal model to simulate the effect of the crust. We investigate two global crustal models to infer crustal contribution on time residual measurements: CRUST2.0 (Bassin et al. 2000) and CRUST1.0 (Laske et al. 2013). Comparison of these two models may prove to be interesting since they show large structural differences (not only in terms of resolution) and they are among the most used crustal models in global tomography. However, these two models are only approximations of the 'true' Earth's crust. Different crustal models will induce differences on time residual measure- 
ments. These differences could be an indication of crustal model uncertainties to be taken into account in global tomographic inversions.

The purpose of this study is therefore to quantitatively estimate the dispersive effect of crust at global scale for these two selected crustal models. We present in a first part how synthetic seismograms are created and which seismic phases are measured. Then we introduce a two-components crustal correction which consist in a ray-theory and a finite-frequency part. We will analyse different factors influencing this "finite-frequency" correction such as sediment thickness. Finally, we show that the finite-frequency part of the correction cannot be neglected compared to the ray-theory part. Except for Obayashi et al. (2004, 2017), previous studies, aiming at correcting those crustal finite-frequency effects, have used a synthetic pre-computed correction and applied it after the measurement process (e.g., Hosseini \& Sigloch 2015). We quantitatively show that a better way to deal with crustal FF effects is to include crustal multiples directly in synthetics before the measurement process. We also show that this can be done with ray-theory based softwares at very low computationnal cost.

\section{SYNTHETIC AND OBSERVED DATA}

The dispersive effect of the crust is explored, first by synthetic experiments at global scale to show the influence of crustal phases on time residuals in different crustal configurations. It allows to understand in a consistent way the crustal phase effects. Then, from a more tomographic point of view, we consider these synthetic examples at real station locations and compare them with observed data. We show in this section how synthetic seismograms are computed and how specific crustal seismic phases are selected. For this purpose, we consider shear waves with specific paths such as S, SS, $\mathrm{ScS}$ (shear waves reflected at the core-mantle boundary), $\mathrm{ScS}_{2}$ (twice core reflected shear waves) and interferences between $\mathrm{S}$ and $\mathrm{ScS}$ at large epicentral distances.

\subsection{Synthetic data}

Green's functions are computed with the Chapman's WKBJ code (Chapman 1978). As inputs, we use the global centroid moment tensor information (Ekström et al. 2012; Dziewonski et al. 1981) and IASP91 (Kennett \& Engdahl 1991) as a 1D reference velocity model. Attenuation corrections have been added by using the Q-model of PREM distributed with the raydyntrace code (Tian et al. 2007). Two different crustal models are considered: CRUST2.0 (Bassin et al. 2000) and CRUST1.0 (Laske et al. 2013). CRUST2.0 is a 7-layers model (ice, water, 2 layers of sediments and 3 layers of crystalline crust) whereas CRUST1.0 is a 8-layers model (same as CRUST2.0 but with an additional sediment layer). CRUST1.0 and CRUST2.0 are specified on a $1^{\circ} \times 1^{\circ}$ and $2^{\circ} \times 2^{\circ}$ grid, respectively. 
To model FF effects from the crust, we generate crustal reverberations induced by impedance contrasts between crustal layers. We use the WKBJ algorithm which allows us to define every phases individually for a given earthquake-station pair and a crustal model. We only include crustal reverberations below the receiver in the synthetic waveform. We are able to model all crustal phases as in the case of reflectivity methods (Keith \& Crampin 1977). However some crustal phases do not influence time residuals measured by cross correlation because of small amplitude or arrival outside the time window selected for the cross-correlation. To save computational time, we select only crustal phases which have a significant impact on time residuals. For this selection, we cross-correlate two synthetics: one with the direct $S$ wave, and the other containing the same $S$ wave and all the associated crustal phases. Then we incrementally remove each crustal phase that do not change the time residual measured by cross-correlation by more than $0.1 \mathrm{~s}$. This test is done over several crustal structures independantly for CRUST1.0 and CRUST2.0. Finally, we end up with a limited set of crustal phases to be systematically included into the synthetics; this set slightly differs for CRUST1.0 and CRUST2.0. This procedure ensures that all important phases are modeled, regardless of the crustal structure, while keeping a reasonnable computational time. By doing that, we include in our synthetics the finite-frequency (FF) effects of the crust (which are not due to intrinsic attenuation).

It is important to notice that a cross-correlation time residual measurement is not only dependent on the Green function but also on the estimated source parameters, such as depth and source time functions (e.g., Hosseini \& Sigloch 2015). As we can note in figure 1, most of earthquakes are shallow events which implies to carefully take into account depth phase interferences. Therefore we model depth phases since it could substantially improve the fit between synthetic and observed waveforms (e.g., Sigloch \& Nolet 2006).

As an additional remark, finite element methods could also be used to compute synthetic seismograms but the crust must be carefully considered. In SPECFEM3D (e.g., Tromp et al. 2008), sediment layers with a thickness of less than a threshold (e.g., $2 \mathrm{~km}$ ) are not considered, thus the meshing for some crustal configuration may miss features of crustal models. Besides, a smoothing is applied on the crustal model which could reduce impedance contrasts between layers and thus decrease the crustal phases impact. As a consequence, major crustal FF effects could be missing if the integration of the crust is not carefully handled in finite element methods.

\subsection{Observed data}

Observed seismograms are retrieved from low noise stations to compare with synthetic seismograms. Stations are selected in order to find a good compromise between low noise levels stations and a good global coverage. We therefore select seismograms from 1976 to March 2017 from 27 networks. Figure 
1 shows the location of stations and events used in this study. We only consider teleseismic earthquakes with magnitude between 5.5 and 6.5 and half-time duration lower than $6 \mathrm{~s}$. This allows us to limit the complexity of the source and we can approximate the source time function by a Gaussian function for the purpose of synthetic calculations (Zaroli et al. 2010). Waveforms and metadata are downloaded from IRIS facilities with the help of obspyDMT (Hosseini \& Sigloch 2017).

\subsection{Measurement process}

We perform finite-frequency measurements on all retrieved seismograms relying on an automated code from Zaroli et al. (2010), which can easily be tuned for measuring specific seismic phases. We measure on five frequency bands: $10 \mathrm{~s}, 15 \mathrm{~s}, 22.5 \mathrm{~s}, 34 \mathrm{~s}$ and $51 \mathrm{~s}$ for a total number of measurements of 628,733 . To face the increasing number of broadband seismometers, it is necessary to handle them in an automatic way. The measurement process can be divided in two main steps. The first one consists in finding the best time window around the target phases in the synthetic and the observed seismograms. The second one involves cross-correlation measurements at different periods using Gaussian filters between the synthetic and the observed seismogram over the previously defined time windows. In order to save memory space, we append to the measurement process the on-the-fly synthetics calculation.

\section{CRUSTAL CORRECTIONS}

Crustal corrections can be divided in two parts: a ray-theory (RT) based correction and a finitefrequency (FF) correction. The RT correction is the ray travel-time acquired when traveling through the crust (under the infinite frequency approximation). RT correction takes into account crustal structure under source, receiver and bouncing points, this correction is frequency independent. The FF correction is due to crustal reverberations which disturb the waveform; this effect strongly depends on the filtering period. We only consider FF crustal effects on the receiver side (for technical reasons related to WKBJ synthetics).

We show in this section how much crustal corrections do matter for teleseismic finite-frequency time residual measurements.

\subsection{Crustal corrections modeling}

\subsubsection{Ray-theory based crustal correction}

The crustal correction based on ray theory is computed from the raydyntrace code (Tian et al. 2007). It represents the ray travel-time difference between the crustal model (CRUST2.0 or CRUST1.0) and the

crust of the 1D reference model (IASP91); it will be refered as $d t_{\text {synth }}^{\text {crust }}$ RT (see Table 1 for a summary 
of the notations used). This correction is frequency independent. Figure 2 compares values of the RT crustal correction for CRUST1.0 and CRUST2.0 at each station. We notice a shift towards negative values for CRUST1.0 compared to CRUST2.0. This indicates that CRUST1.0 under stations is on average faster than CRUST2.0.

Crustal models have a limited resolution ( $1^{\circ}$ for CRUST1.0 and $2^{\circ}$ for CRUST2.0), thus about $22 \%$ of our stations have a water layer in their crustal models as we can see in figure 2 (water layers have been removed for synthetic computation). Stations with green crosses indicate that continental stations are considered as oceanic (with a water layer) in CRUST2.0. Most of continental stations considered as oceanic are common for both crustal models. The number of stations with a water layer is larger for CRUST1.0 (107) than CRUST2.0 (87). At the bottom left corner, all stations have a water layer for both crustal models and a very thin sediment layer; these stations are set up on islands. Stations located at the top right corner of figure 2 have high positive RT corrections and a thick sediment layer; they correspond to coastal stations where sediment thickness may be important. RT crustal corrections larger than $3 \mathrm{~s}$ for CRUST2.0 correspond to continental stations but with significant changes in elastic parameters or layer thicknesses compared to CRUST1.0. For example, the station GO02 (Chilean network, station with a RT correction for a S wave larger than $4 \mathrm{~s}$ for CRUST2.0) has a crustal thickness of $70 \mathrm{~km}$ for CRUST2.0 but only $40 \mathrm{~km}$ for CRUST1.0. Such crustal variations induce differences in the RT correction up to $4 \mathrm{~s}$ between CRUST1.0 and CRUST2.0.

\subsubsection{Finite-frequency crustal correction}

The FF crustal correction arises from waveform distortions whereas RT crustal correction is a static shift of the main seismic waveform of interest. We define the finite-frequency crustal correction as the time residual measured between a synthetic seismogram with all relevant crustal phases and a synthetic without crustal phases. We can express this correction as:

$$
d t_{\text {synth }}^{\text {crust, } \mathrm{FF}}(T)=t_{\text {synth }}^{\mathrm{CP}}(T)-t_{\text {synth }}^{\mathrm{NCP}}(T)
$$

where CP refers to synthetics modeled with crustal phases, and NCP refers to synthetics computed with no crustal phases and $T$ is the central filtering period at which we measure a time residual by cross-correlation. Figure 3 shows an example of the importance of taking into account crustal phases in time residual estimations at different periods. We cross-correlate two synthetic seismograms: one composed of the S-wave alone (black waveform) and one composed of the S-wave with all relevant crustal multiples (blue waveform), broadband filtered between 7-81 s. Off course we add supplementary reflections for CRUST1.0 model to handle the additionnal sediment layer. In figure 3a, the dispersion curve shows time residuals measured at different periods with their error bars, as a remark, 
error bars are not always smaller at long periods than at short periods. There is a clear decreasing trend which is present at almost all stations. For this particular example, there is a difference of $1.8 \mathrm{~s}$ between measurements made at $10 \mathrm{~s}$ and at $51 \mathrm{~s}$ period. If not corrected from the crust, this difference between time residuals measured at two different periods would be considered as mantle-structure related dispersion. One can note that broadband measurement in figure $3 \mathrm{~b}$ shows a time-shift of $-0.4 \mathrm{~s}$ between the two waveforms $\left(d t_{\mathrm{BB}}=-0.4 \mathrm{~s}\right)$. Figure A1 shows another synthetic example of the influence of crustal phases on time residual estimation in a different geological context without sediment layers.

For the purpose of better understanding the crustal structure influence over time residuals measurements, cross-correlations of $\mathrm{S}$ waves alone and $\mathrm{S}$ waves with crustal phases are made over each cell of crustal models. Figure 4 presents global time residuals measured at $22.5 \mathrm{~s}$ period between an $\mathrm{S}$-wave alone and an S-wave with crustal multiples for CRUST1.0, on a $1^{\circ} \times 1^{\circ}$ grid. We use a year of seismicity and model $\mathrm{S}$ waves as well as $\mathrm{ScS}$ waves to investigate epicentral distances between $30^{\circ}$ and $95^{\circ}$. For these measurements, we apply the same workflow as for observed data. First we can note a clear bias towards negative time residuals and so a clear non-zero mean for FF crustal corrections. We show waveforms filtered at $22.5 \mathrm{~s}$ including or not crustal phases (blue and black curves respectively) in two different crustal configurations. According to the location, synthetics with crustal phases may significantly be different from synthetics without crustal phases. Besides, crustal phases can have a delaying or an advancing effect on the time residual measured by cross-correlation, depending on the local crustal structure.

Figure 5 compares FF crustal corrections between CRUST1.0 and CRUST2.0 at every station filtered at $22.5 \mathrm{~s}$ period. Although median values of FF crustal corrections are similar for CRUST1.0 and CRUST2.0, one sees that FF crustal corrections for CRUST1.0 are much more dispersed (between $0.3 \mathrm{~s}$ and $-5.2 \mathrm{~s}$ ) than for CRUST2.0 (between $0 \mathrm{~s}$ and $-3.3 \mathrm{~s}$ ). Most stations for CRUST1.0 with large negative FF correction (lower than $-1.5 \mathrm{~s}$ ) have a water layer in their crustal model. Variability of FF corrections for CRUST1.0 is mainly noticeable for insular or coastal stations. For coastal stations which have a water layer we could take the closer continental crust from this station, though we cannot ensure the reliability of this crust model neither. Besides the problem is still present for insular stations, where taking the closer continental crust does not mean much especially for volcanic islands. On the left side of figure 5, five stations have FF crustal corrections lower than $-2.2 \mathrm{~s}$ for CRUST2.0; they correspond to inland Greenland stations and the Concordia station (in Antartica).

Continent-ocean contrast is much more important for CRUST1.0 than CRUST2.0 (see fig. 6). Mean time residuals for CRUST1.0 are more dispersed than those for CRUST2.0, differences are however less striking and more comparable for continental values. For CRUST2.0, deep oceanic regions seem less highlighted than margins and regions where sediment thicknesses are large. This feature 
is emphasized for CRUST1.0 model where time residuals reach $-2 \mathrm{~s}$ at margins. Some continental regions in CRUST1.0 almost have a zero mean which implies no FF influence from the crust, only the RT correction needs to be applied. Zero-mean regions seem to be correlated with specific geological settings such as old shields and orogens (India, North-West Canada, Scandinavia) with large crustal thickness and no low-velocity layers. This is in agreement with observations made by Kolstrup \& Maupin (2015) in the Scandinavia region.

We show in figure 6 the sediment thickness for CRUST1.0 and CRUST2.0 aside with associated FF crustal corrections. At $22.5 \mathrm{~s}$, larger values of FF crustal corrections in oceanic regions are not directly correlated to large sediment thickness but rather to the borders of thick sediment piles (light blue/green colors). There is no direct correlation because FF crustal effects depend on both crustal structure and the main frequency content of the wave. Indeed at low frequencies high negative values for FF crustal corrections can be seen on regions with various sediment thicknesses (see evolution of worldmap colors as function of period in fig. A6). For a filtering period of $22.5 \mathrm{~s}$, crustal phases generated by very thin layers with high velocities will arrive simultaneously with the main phase and so the shape of waveform will not be disturbed (only its amplitude). Crustal phases from thick layers with low velocities will arrive much later than the main phase and will not influence its waveform. The complex combination of layer thicknesses and elastic impedance contrasts makes it difficult to interpret variations of FF crustal effects over various geological settings. Since low frequency filtering broadens waveforms, crustal phases are more likely to interfere with the target waveform. Measurements made at low frequency are thus more affected by crustal reverberations than at high frequency.

Recent studies underline the fundamental effect of sediments, i.e., low-velocity layers, on FF crustal effects (Kolstrup \& Maupin 2015). For the Scandinavia region they point out large FF effects when low-velocity sediment layers are under stations; but they also show no significant FF effects for crustal thickness variations. Here, we would like to further assess the FF crustal effects as a function of sediment thickness when considering various specific regions. Figure 7 aims to show the effect of sediment thickness on finite-frequency crustal corrections at different periods for all stations. Sediment thickness is the sum of the sediment layers and of the ice layer. At first sight, correlation between sediment thickness and FF crustal corrections is not straightforward. Off course, variability in timeresiduals reflects the complexity of CRUST1.0. Nevertheless, we can notice that as we increase the filtering period, FF crustal corrections $\left(d t_{\text {synth }}^{\text {crust1, FF }}(T)\right.$ ) increase in absolute value (also clearly visible in figures A4-A6) which supports observations made by Obayashi et al. (2004) on the importance of crustal phases especially at low frequency. Besides, as we move towards lower frequencies the range of sediment thicknesses with large time residuals broadens. This is coherent with geographical information in figure A6 where at low frequency high negative time residuals are correlated with 
various sediment thicknesses and therefore cover a wider geographical area. Moreover, one can note the presence of a decreasing trend for stations with thin crustal thickness (yellow dots). This quasilinear trend (see figure A3) appears for stations with sediment thickness between 0.5 and $1.5 \mathrm{~km}$ and very thin crustal thickness $(<12 \mathrm{~km})$. The effect of sediment thickness is maximal for low frequency waves $(\mathrm{T}=51 \mathrm{~s})$ and disappears at high frequency $(\mathrm{T}=10 \mathrm{~s})$, since all crustal phases do not interfere with high frequency waves. Stations with thin oceanic crust seem to be more influenced by sediment thickness compared to other stations. In figure A3, one clearly sees the strong increase of FF crustal effects when sediment thickness increases. It is however difficult to state that FF crustal correction is clearly correlated to sediment thickness for non-oceanic stations. As we can see, sediment thickness is not the only critical parameter. Thickness and velocity parameters control the time arrival of crustal phases, while elastic impedance contrasts rather control the amplitude of crustal phases. That is why relevant crustal phases arrive in a specific time range, after the main phase, with large amplitude (high energy) to truly disturb the main seismic waveform. These conditions make FF crustal corrections not straightforward to estimate a priori (e.g., Kolstrup \& Maupin 2015) and in any case only dependent on sediment thickness but on the whole crustal structure (see example of Gulf of Mexico in section 3.2.2).

\subsubsection{Ray-theory versus finite-frequency crustal corrections}

Figure 8 shows synthetic FF corrections versus RT corrections for all stations for CRUST2.0 (blue) and CRUST1.0 (red). These corrections are plotted in absolute value for periods 10, 15, 34 and 51 s $\left(\left|d t_{\text {synth }}^{\text {crust, FF }}(T)\right|\right)$. We see that dispersion in FF correction increases with the period, while RT correction remains constant for all periods. Geological setting under stations (thicknesses and shear-wave velocities in layers) are the only cause for the variability in RT corrections as they are independent of the filtering period. Medians of FF crustal corrections for CRUST2.0 are always larger than for CRUST1.0, but variability of FF corrections is larger for CRUST1.0 than CRUST2.0. As we can see, CRUST2.0 has medians for FF crustal effects always very different from RT crustal corrections at all periods compared to CRUST1.0. We can note that some points outline horizontal or vertical lines. Some of these lines can be linked to stations with common features such as without sediment layers: see dots around $0.5 \mathrm{~s}$ for FF delay with CRUST2.0 (Figure 8a). It is however complex to relate each line to a specific set of stations especially when period increases.

Since the crustal correction is composed of two terms; i.e., ray-theory crustal correction and finitefrequency crustal correction, we can assess the total crustal contribution to time residuals measured at different periods. For a S-wave, the mean and the standard deviation of the crustal correction at $10 \mathrm{~s}$ period are $0.7 \mathrm{~s} \pm 1.1 \mathrm{~s}$ for CRUST 2.0 and $0.9 \mathrm{~s} \pm 1.0 \mathrm{~s}$ for CRUST1.0. For a period of $51 \mathrm{~s}$, the mean 
and the standard deviation are $1.4 \mathrm{~s} \pm 1.1 \mathrm{~s}$ for CRUST2.0 and $2.1 \mathrm{~s} \pm 1.8 \mathrm{~s}$ for CRUST1.0. Therefore, crust may induce effects of mostly the same order of magnitude as for measured time residuals.

\subsection{Finite-frequency crustal effects estimated from observed data}

We show in this section how FF crustal corrections estimated from observed data are coherent with those obtained from synthetic experiments.

\subsubsection{Statistics on observed data}

Fig. 9 shows histograms of measured $\mathrm{S}$ and $\mathrm{ScS}$ time residuals at $10 \mathrm{~s}, 22.5 \mathrm{~s}$ and $51 \mathrm{~s}$ central periods, including interferences with their depth phases ( $\mathrm{sS}$ and $\mathrm{sScS}$ respectively) for both crustal models. S-wave time-residual histograms seems to be nearly gaussian distributed except at 51s where we can notice a strong asymmetry (long tail toward negative time residuals). Distributions for $\mathrm{ScS}$ wave have heavy tails unlike the gaussian shape with noticeably asymmetry for 51s toward positive delays. These asymmetries for $\mathrm{S}$ and $\mathrm{ScS}$ waves at $51 \mathrm{~s}$ could be due to their mutual interferences (at large epicentral distance); at short period these waves are less prone to interfere than at long periods.

We notice that time residuals measured for the two different crustal models are not so different on average. At $10 \mathrm{~s}$ period, we have a mean time-shift of $0.3 \mathrm{~s}$ for CRUST2. 0 and of $0.5 \mathrm{~s}$ for CRUST1.0, and at $51 \mathrm{~s}$ we have $2.5 \mathrm{~s}$ and $2.4 \mathrm{~s}$ respectively. It is difficult to distinguish those two datasets processed with two different crustal models only based on histograms. However, measurements at specific stations can be significantly different between the two crustal models.

We are working with shear waves generated by earthquakes occuring at different depths. Therefore, for shallow depths it is impossible to measure $S$-wave alone since the arrival of the depth phase $(\mathrm{sS})$ is very close to the main phase (S). In these cases we measure $\mathrm{S}$ waves with their associated depth phases. We carry out the same statistics by keeping only deep events to get rid of depth phase interference problem. Except the number of measurements, time residual distributions for different periods are significantly the same as for figure 9 .

\subsubsection{Crustal phases impact on observed data}

Figure 10 shows histograms of measurements and mean dispersion curves for S-wave and ScS-wave measurements (results for SS and $\mathrm{ScS}_{2}$-waves are shown in figure A2). On the bottom row of figure 10, histograms represent the number of measurements obtained with and without crustal phases for CRUST2.0. We see for $\mathrm{S}$ and $\mathrm{ScS}$ waves, and at almost all periods, that we increase of measurements 
by including crustal phases in synthetic seismograms. This observation can be explained by a better fit between observed and synthetic waveforms when including crustal reverberations in the synthetic.

The top row of figure 10 shows the mean of all our $\mathrm{S}$ and $\mathrm{ScS}$ dispersion curves for CRUST2.0 and CRUST1.0; dashed lines indicate dispersion curves when crustal phases are not taken into account in synthetics. First, we can notice a clear difference between curves with and without crustal phases which implies an influence of crustal phases on cross-correlation measurements. Inclusion of crustal phases for S and SS induces an important shift (downward) of dispersion curves, though it is weaker for $\mathrm{ScS}$ and $\mathrm{ScS}_{2}$ (in particular with CRUST2.0). For $\mathrm{ScS}$ measurements, crustal models are almost indistinguishable on dispersion curves. This may imply a strong influence coming from the lower mantle which overcomes the crustal influence. Time residuals in figure 10 are corrected for dispersion induced by intrinsic anelastic attenuation assuming a frequency-independent quality factor $\mathrm{Q}$. As a remark, one could also correct for a frequency-dependent quality factor and thus remove remaining dispersive effects observed on mean S-wave time residuals. Zaroli et al. (2010) show that it is possible to have an almost horizontal dispersion curve by tuning a parameter controlling the frequency dependency of the quality factor (at least for S and SS data).

\subsubsection{Estimations of finite-frequency crustal effects with observed data}

We aim to extract the finite-frequency crustal effects from measurements derived from observed seismograms (figure 11). Worldmap colors represent the synthetic FF crustal correction for CRUST1.0 and CRUST2.0 at $22.5 \mathrm{~s}$ period and colored triangles are the observed FF crustal effect extracted from measurements with observed data plotted at station locations. To estimate the FF crustal effect from observed data, we average for each station the time residual differences between measurements made by including or not crustal phases in synthetics, such as:

$$
\Delta d t_{\mathrm{obs}}^{\mathrm{crust}, \mathrm{FF}}(T)=d t_{\mathrm{obs}}^{\mathrm{CP}}(T)-d t_{\mathrm{obs}}^{\mathrm{NCP}}(T)
$$

with $T$ the period at which the time residual has been measured. Thus we are trying to isolate the effect of crustal phases on time residuals on observed data. Figures A4 and A5 show results at different periods for CRUST1.0 and CRUST2.0, respectively. Most stations (triangle colors) indicate that time residuals measured by including crustal multiples are different from those measured without crustal phases (i.e. $d t_{\mathrm{obs}}^{\mathrm{CP}}(T) \neq d t_{\mathrm{obs}}^{\mathrm{NCP}}(T)$ ). FF crustal corrections extracted from observed data are mostly negative which is consistent with FF crustal correction estimated from synthetics (see green dots in Fig. 11). We see that FF crustal corrections estimated from observed data are quite coherent with estimations from synthetics (follow the trend $\mathrm{y}=\mathrm{x}$ ). Although there are strong deviations for some 
stations, the global pattern is coherent. Strong data dispersion $(>3 \mathrm{~s})$ may come from discrepancies between crustal models and the true structure of the crust under some stations. For instance, TBT (Canary island) station has a water layer with a very soft sediment layer in CRUST1.0; however the geological map of this region indicates volcanic rocks (basalt). Similar effects can be noticed on observed data by using CRUST2.0 (Figure 11 bottom row). We note that points distribution for CRUST1.0 (Figure 11 top row) is more spread than for CRUST2.0 (Figure 11 bottom row). However, one may note that crossplots computed with CRUST2.0 are not centered on the $y=x$ line (i.e. black dashed line) but green points are slightly shifted towards the upper left corner, unlike for CRUST1.0 where green points are well centered.

Figure 12 is a zoom on the Mediterranean and North American regions, where seismic networks are dense. We see on the top row FF crustal effects for CRUST1.0 at $22.5 \mathrm{~s}$ computed from synthetics plotted as worldmap colors and those estimated from data as colored triangles. On the middle and bottom rows, we have the sediment and crystalline crustal thickness respectively associated to these regions. In these two areas, we have a very good agreement between synthetic and observed FF crustal estimations. Clear features of the crust previously highlighted by synthetic experiments are visible on observed data measurements ( $d t_{\text {synth }}^{\text {crust1, FF }}(T) \simeq \Delta d t_{\text {obs }}^{\text {crust1, FF }}(T)$ for most stations). Scandinavia region located in the upper part of the Europe map (left column) shows good agreement with Kolstrup \& Maupin (2015), that is, weak FF correction for the north-eastern area and negative FF correction for Norway coast and Denmark due to low-velocity sediment layers. Off course, differences in terms of resolution of the two crustal models prohibits a finer analysis. It is noteworthy from figure 12 that sediment layers influence FF crustal effects. In North America, all regions with no sediment have a FF crustal correction equal to zero. But FF crustal variations cannot only be explained by sediment thickness variations, since several FF crustal features are not depicted in sediment maps. For instance, the northern part of the Gulf of Mexico exhibits a large and constant sediment thickness, but with very different FF responses. This thick sediment layer (dark red) overlaps continental and oceanic regions with very different crustal thickness. Consequently, in this specific case, the same sediment thickness for an oceanic crust induces a positive anomaly whereas it induces a negative anomaly for a continental crust. Figure A6 is a zoom in North America for CRUST2.0 and CRUST1.0 at all periods. By combining figures 12 and A6, we see that regions with the thickest sediment layers are not those where FF corrections are the largest for all periods, but they are characterized by strong crust-related finite-frequency variations. Time residuals measured at continental stations vary much less than those computed at oceanic stations (figure A6)

Gulf of Mexico shows a positive anomaly for periods from $10 \mathrm{~s}$ to $22 \mathrm{~s}$ and then a negative anomaly for $34 \mathrm{~s}$ and $51 \mathrm{~s}$. Analysis of the crustal structure in CRUST1.0 shows that this region has a very thick 
sediment pile with three sediment layers in the Gulf, whereas there are only two sediment layers in adjacent regions (Cuba and Mexico). The two first sediment layers have strong shear-wave velocity contrasts. Besides, the sediment sequence is clearly thicker than the crystalline part of crust. We think strong elastic impedance contrasts between crustal layers and large sediment thicknesses (Fig. 12) could induce this change in the sign of the anomaly in the Mexico bassin. In the models used, no other region has such a crust configuration with the exception of the eastern part of the Mediterranean sea.

From all these observations we can conclude that CRUST1.0 may be in general a better representation of the crust under stations than CRUST2.0. Indeed, comparisons of FF time residuals between synthetics and data ( Figures A4 and A5, rigth panel) show that dots for CRUST2.0 are not aligned along the $y=x$ line (i.e. black dashed line) but is slightly shifted unlike CRUST1.0. This could be an indication that CRUST1.0 is on average a better representation of the true crust below stations, even if there are more outliers in CRUST1.0 (i.e., dots far from $\mathrm{y}=\mathrm{x}$ ) than in CRUST2.0 (see right-hand plots in fig.11). This spreading in CRUST1.0 crossplot reflects structural variations which could be in some cases worst than CRUST2.0 which is a coarser crustal model. Therefore, it is difficult to state that one specific crustal model is everywhere better than another (i.e., for all stations); accuracy of crustal models are completely station-dependent; CRUST1.0 is the best representation for some stations, for others, CRUST2.0 is better, and sometimes neither of them is a good representation of the unknown true crust.

\section{CONCLUSION}

We have shown that the crust has a major dispersive effect on teleseismic body-wave time residuals and thus needs to be properly accounted for. Integration of crustal phases in synthetic seismograms allows to take into account waveform distortions induced by the crust structure when measuring time residuals by cross-correlation technique. Crustal effects may differ at different frequencies, since they reflect the inherent complexity of three-dimensional (3-D) crust.

We have explored two 3-D crustal models: CRUST1.0 and CRUST2.0. We report that dispersive crustal effects depend on the thickness and velocity of layers as well as elastic impedance contrasts between layers. Although ray crustal corrections remain important, finite-frequency crustal effects may lead to a bias in measurements and on average may reach $0.9-1.6 \mathrm{~s}$ for CRUST2.0 and 0.5-1.6 s for CRUST1.0, for filtering central period ranging from 10-51 s, respectively. As a consequence, we report clear differences of crustal corrections between CRUST1.0 and CRUST2.0. For shear waves (S, ScS, SS), the mean and the standard deviation of the total crustal correction (ray-theory and finitefrequency) at $10 \mathrm{~s}$ are $0.7 \mathrm{~s} \pm 1.1 \mathrm{~s}$ for CRUST 2.0 and $0.9 \mathrm{~s} \pm 1.0 \mathrm{~s}$ for CRUST1.0. At $51 \mathrm{~s}$ period, the mean and the standard deviation are $1.4 \mathrm{~s} \pm 1.1 \mathrm{~s}$ for CRUST2.0 and $2.1 \mathrm{~s} \pm 1.8 \mathrm{~s}$ for CRUST1.0. We 
have shown that if this crust-related correction is not taken into account in cross-correlation measurements, this may lead to a significant dispersive effect in S-wave delay-times that could ultimately bias tomographic models.

\section{ACKNOWLEDGMENTS}

The authors thank the editor Martin Schimmel, and Kasra Hosseini and an anonymous reviewer for constructive comments that helped to futher clarify this paper. We would like to thank all the members of the following seismological networks: G, II, IU, US, CN, GT, AF, GE, C, CH, CI, CZ, DK, EI, IC, KN, MN, MY, NA, ND, NL, NZ, OV, PL, PM, PS, TW for setting up stations, taking care of the seismometers maintenance and distributed data for the seismological community. The facilities of IRIS Data Services, and specifically the IRIS Data Management Center, were used for access to waveforms and related metadata. IRIS Data Services are funded through the Seismological Facilities for the Advancement of Geoscience and EarthScope (SAGE) Proposal of the National Science Foundation under Cooperative Agreement EAR-1261681.

\section{REFERENCES}

Bassin, C., Laske, G., \& Masters, G., 2000. The current limits of resolution for surface wave tomography in North America, Eos, 81.

Bolton, H. \& Masters, G., 2001. Travel times of P and S from the global digital seismic networks: Implications for the relative variation of $\mathrm{P}$ and $\mathrm{S}$ velocity in the mantle, Journal of Geophysical Research: Solid Earth, 106(B7), 13527-13540.

Chapman, C. H., 1978. A new method for computing synthetic seismograms, Geophysical Journal of the Royal Astronomical Society, 54(3), 481-518.

Chevrot, S., 2002. Optimal measurement of relative and absolute delay times by simulated annealing, Geophysical Journal International, 151(1), 164-171.

Dahlen, F., Hung, S.-H., \& Nolet, G., 2000. Fréchet kernels for finite-frequency traveltime-I. Theory, Geophysical Journal International, 141(1), 157-174.

Dziewonski, A., Chou, T.-A., \& Woodhouse, J., 1981. Determination of earthquake source parameters from waveform data for studies of global and regional seismicity, Journal of Geophysical Research: Solid Earth, 86(B4), 2825-2852.

Ekström, G., Nettles, M., \& Dziewoński, A., 2012. The global CMT project 2004-2010: Centroid-moment tensors for 13,017 earthquakes, Physics of the Earth and Planetary Interiors, 200, 1-9.

Fukao, Y., To, A., \& Obayashi, M., 2003. Whole mantle P wave tomography using P and PP-P data, Journal of Geophysical Research: Solid Earth, 108(B1), ESE-8. 
Hosseini, K. \& Sigloch, K., 2015. Multifrequency measurements of core-diffracted P waves (Pdiff) for global waveform tomography, Geophysical Journal International, 203(1), 506-521.

Hosseini, K. \& Sigloch, K., 2017. obspyDMT: A Python toolbox for retrieving and processing of large seismological datasets.

Hung, S.-H., Shen, Y., \& Chiao, L.-Y., 2004. Imaging seismic velocity structure beneath the Iceland hot spot: A finite frequency approach, Journal of Geophysical Research: Solid Earth, 109(B8).

Kárason, H. \& Hilst, R. D., 2001. Tomographic imaging of the lowermost mantle with differential times of refracted and diffracted core phases (pkp, pdiff), Journal of Geophysical Research: Solid Earth, 106(B4), 6569-6587.

Keith, C. M. \& Crampin, S., 1977. Seismic body waves in anisotropic media: reflection and refraction at a plane interface, Geophysical Journal International, 49(1), 181-208.

Kennett, B. \& Engdahl, E., 1991. Traveltimes for global earthquake location and phase identification, Geophysical Journal International, 105(2), 429-465.

Kolstrup, M. \& Maupin, V., 2015. Measuring and crust-correcting finite-frequency travel time residualsapplication to southwestern Scandinavia, Solid Earth, 6(4), 1117-1130.

Laske, G., Masters, G., Ma, Z., \& Pasyanos, M., 2013. Update on CRUST1. 0-A 1-degree global model of Earths crust, in Geophys. Res. Abstr, vol. 15, p. 2658, EGU General Assembly Vienna, Austria.

Masters, T. G., Johnson, S., Laske, G., \& Bolton, H., 1996. A shear-velocity model of the mantle, Phil. Trans. R. Soc. Lond. A, 354(1711), 1385-1411.

Montelli, R., Nolet, G., Dahlen, F., Masters, G., Engdahl, E. R., \& Hung, S.-H., 2004. Finite-frequency tomography reveals a variety of plumes in the mantle, Science, 303(5656), 338-343.

Montelli, R., Nolet, G., Dahlen, F., \& Masters, G., 2006. A catalogue of deep mantle plumes: New results from finite-frequency tomography, Geochemistry, Geophysics, Geosystems, 7(11).

Nolet, G. et al., 2008. A breviary of seismic tomography, Imaging the Interior.

Obayashi, M., Suetsugu, D., \& Fukao, Y., 2004. PP-P differential traveltime measurement with crustal correction, Geophysical Journal International, 157(3), 1152-1162.

Obayashi, M., Ishihara, Y., \& Suetsugu, D., 2017. Effects of shallow-layer reverberation on measurement of teleseismic P-wave travel times for ocean bottom seismograph data, Earth, Planets and Space, 69(1), 44.

Ritsema, J., Van Heijst, H., Woodhouse, J., \& Deuss, A., 2009. Long-period body wave traveltimes through the crust: implication for crustal corrections and seismic tomography, Geophysical Journal International, 179(2), 1255-1261.

Ritsema, J., Deuss, a. A., Van Heijst, H., \& Woodhouse, J., 2011. S40RTS: a degree-40 shear-velocity model for the mantle from new rayleigh wave dispersion, teleseismic traveltime and normal-mode splitting function measurements, Geophysical Journal International, 184(3), 1223-1236.

Schaff, D., Waldhauser, F., Kim, W., \& Richards, P., 2001. Cross-correlation measurements and the doubledifference earthquake location technique, in AGU Fall Meeting Abstracts.

Schaff, D. P. \& Waldhauser, F., 2005. Waveform cross-correlation-based differential travel-time measurements 
at the northern california seismic network, Bulletin of the Seismological Society of America, 95(6), 24462461.

Shearer, P. M., 1997. Improving local earthquake locations using the 11 norm and waveform cross correlation: Application to the whittier narrows, california, aftershock sequence, Journal of Geophysical Research: Solid Earth, 102(B4), 8269-8283.

Sigloch, K. \& Nolet, G., 2006. Measuring finite-frequency body-wave amplitudes and traveltimes, Geophysical Journal International, 167(1), 271-287.

Tian, Y., Hung, S.-H., Nolet, G., Montelli, R., \& Dahlen, F. A., 2007. Dynamic ray tracing and traveltime corrections for global seismic tomography, Journal of computational physics, 226(1), 672-687.

Tromp, J., Komattisch, D., \& Liu, Q., 2008. Spectral-element and adjoint methods in seismology, Communications in Computational Physics, 3(1), 1-32.

Woodward, R. L. \& Masters, G., 1991a. Global upper mantle structure from long-period differential travel times, Journal of Geophysical Research: Solid Earth, 96(B4), 6351-6377.

Woodward, R. L. \& Masters, G., 1991b. Lower-mantle structure from ScS-S differential travel times, Nature, 352(6332), 231-233.

Yang, T. \& Shen, Y., 2006. Frequency-dependent crustal correction for finite-frequency seismic tomography, Bulletin of the Seismological Society of America, 96(6), 2441-2448.

Yang, T., Shen, Y., van der Lee, S., Solomon, S. C., \& Hung, S.-H., 2006. Upper mantle structure beneath the Azores hotspot from finite-frequency seismic tomography, Earth and Planetary Science Letters, 250(1-2), $11-26$.

Zaroli, C., Debayle, E., \& Sambridge, M., 2010. Frequency-dependent effects on global S-wave traveltimes: wavefront-healing, scattering and attenuation, Geophysical Journal International, 182(2), 1025-1042.

Zaroli, C., Lambotte, S., \& Lévêque, J.-J., 2015. Joint inversion of normal-mode and finite-frequency S-wave data using an irregular tomographic grid, Geophysical Journal International, 203(3), 1665-1681. 
Table 1. Meaning of main symbols used in this study. All these symbols have seconds as physical unit.

\begin{tabular}{ll}
\hline Symbol & Meaning \\
\hline$d t_{\text {synth }}^{\text {crust, RT }}$ & ray-theory crustal correction computed for CRUST1.0/CRUST2.0 with raydyntrace \\
$d t_{\mathrm{synth}}^{\text {crust, FF }}(T)$ & $\begin{array}{l}\text { finite-frequency crustal correction for CRUST1.0/CRUST2.0 computed by cross- } \\
\text { correlating two synthetics (with and without crustal phases) filtered around the period } \\
\end{array}$ \\
$\Delta d t_{\mathrm{obs}}^{\text {crust, FF }}(T)$ & $\begin{array}{l}\text { finite-frequency crustal correction for CRUST1.0/CRUST2.0 model estimated on ob- } \\
\text { served data by taking the difference between time-residuals measured with and with- } \\
\end{array}$ \\
$d t t_{\mathrm{obs}}^{\mathrm{CP}}(T)$ & $\begin{array}{l}\text { out crustal phases, filtered around the period } T \\
\text { time-residual measured between a synthetic and an observed data by including crustal }\end{array}$ \\
$d t_{\mathrm{obs}}^{\mathrm{NCP}}(T)$ & $\begin{array}{l}\text { phases (CP) in synthetics, filtered around period } T \\
\text { crustal phases (NCP) in synthetics, filtered around the period } T\end{array}$ \\
&
\end{tabular}




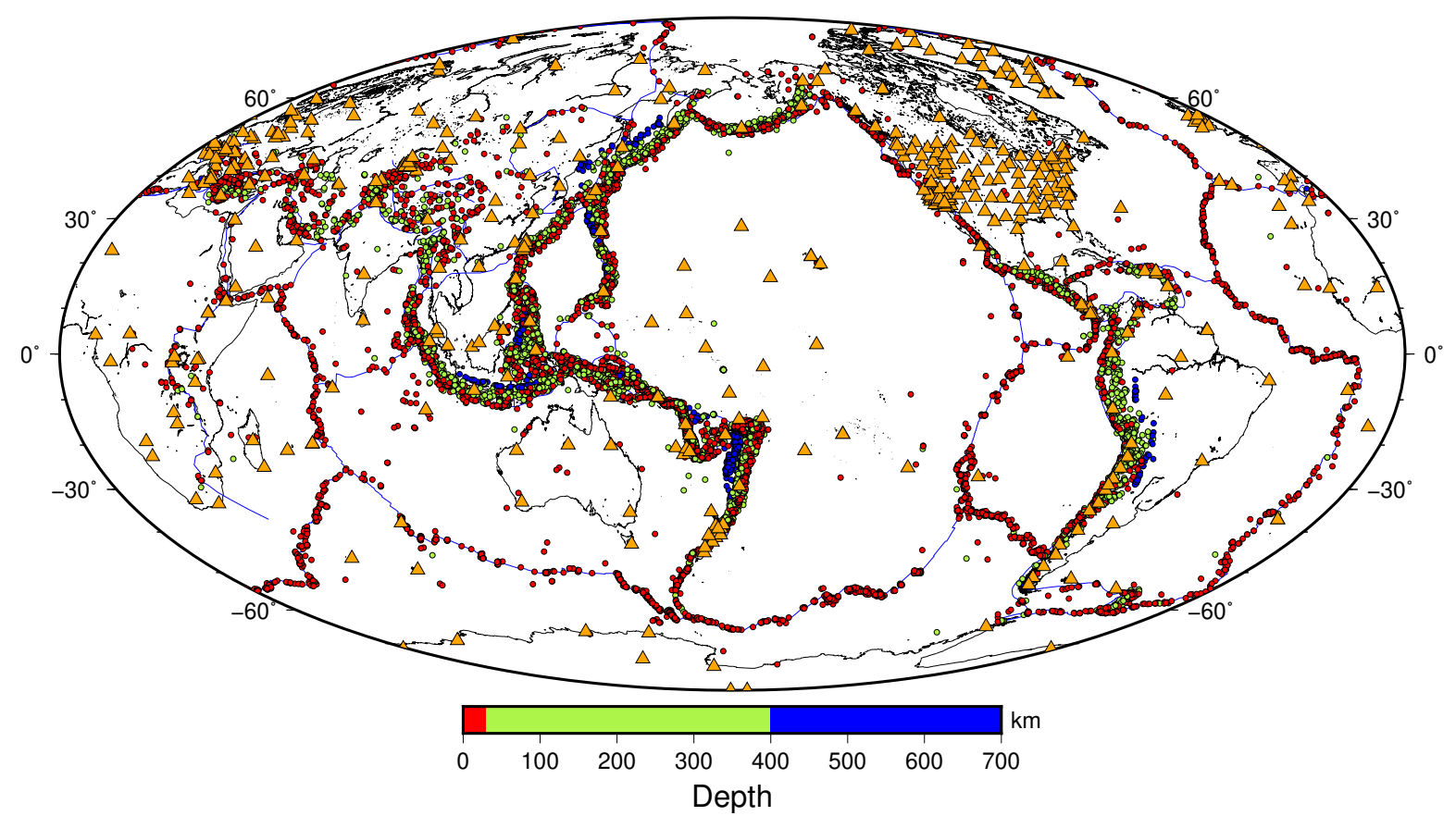

Figure 1. Source-receiver distribution for the shear wave dataset: location of broad-band stations (orange triangles), and selected earthquakes with $5.5<M_{w}<6.5$ from the GCMT catalog (circles filled with depthdependent colors). Color transitions are at $30 \mathrm{~km}$ and $400 \mathrm{~km}$ of depth. Borders of continental plates are indicated by a blue contour. 

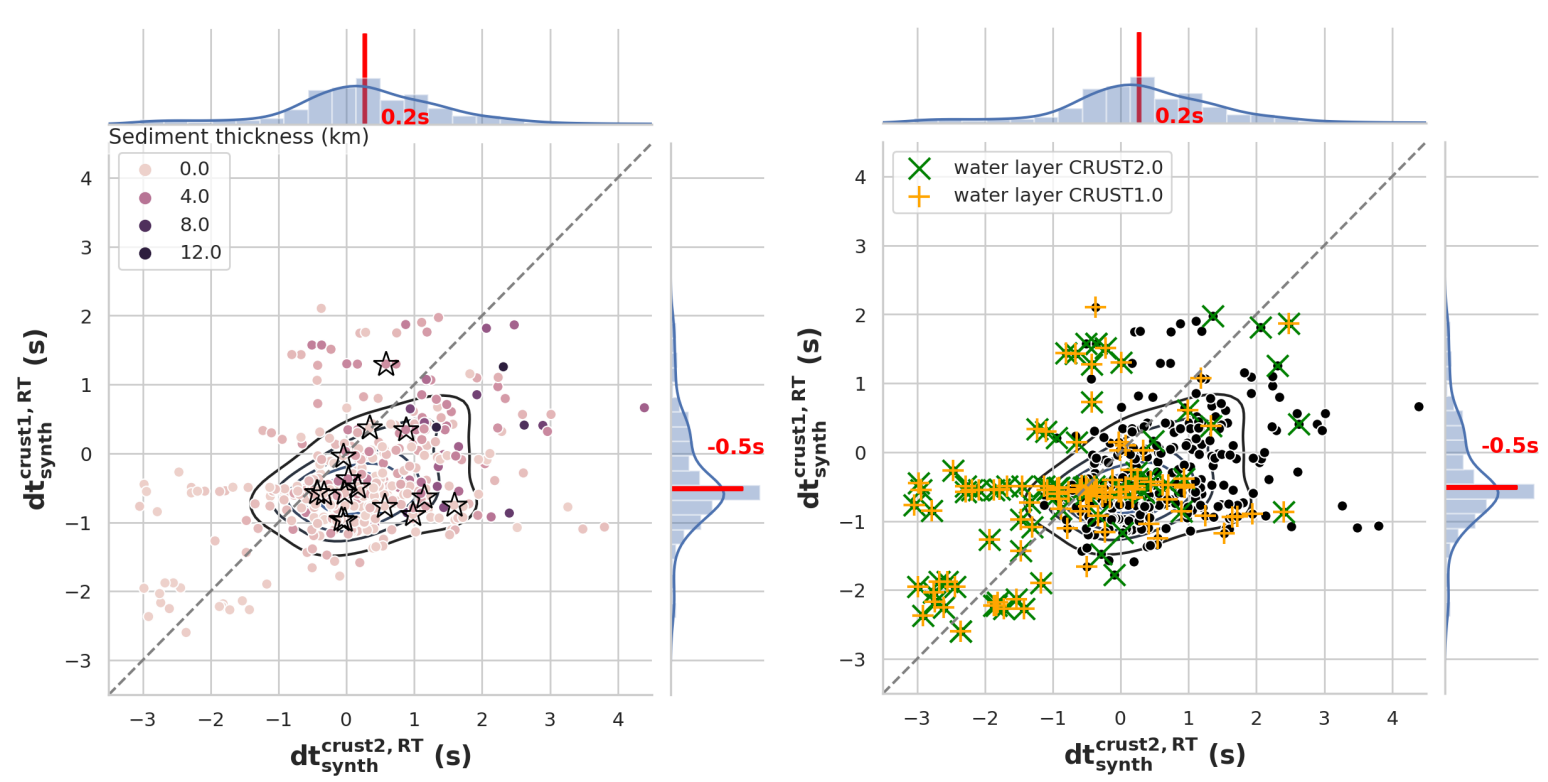

Figure 2. Ray-theory based crustal corrections computed for all stations using CRUST1.0 and CRUST2.0, red bars on histograms indicate the distribution medians. (Left) Color scale represents the sediment thickness under each station in km (mean of CRUST1.0 and CRUST2.0), stations with ice layer are represented by black stars. (Right) Green and orange crosses indicate stations which have a water layer in CRUST2.0 and in CRUST1.0 respectively. We used the raydyntrace software (Tian et al. 2007) to compute these corrections. 

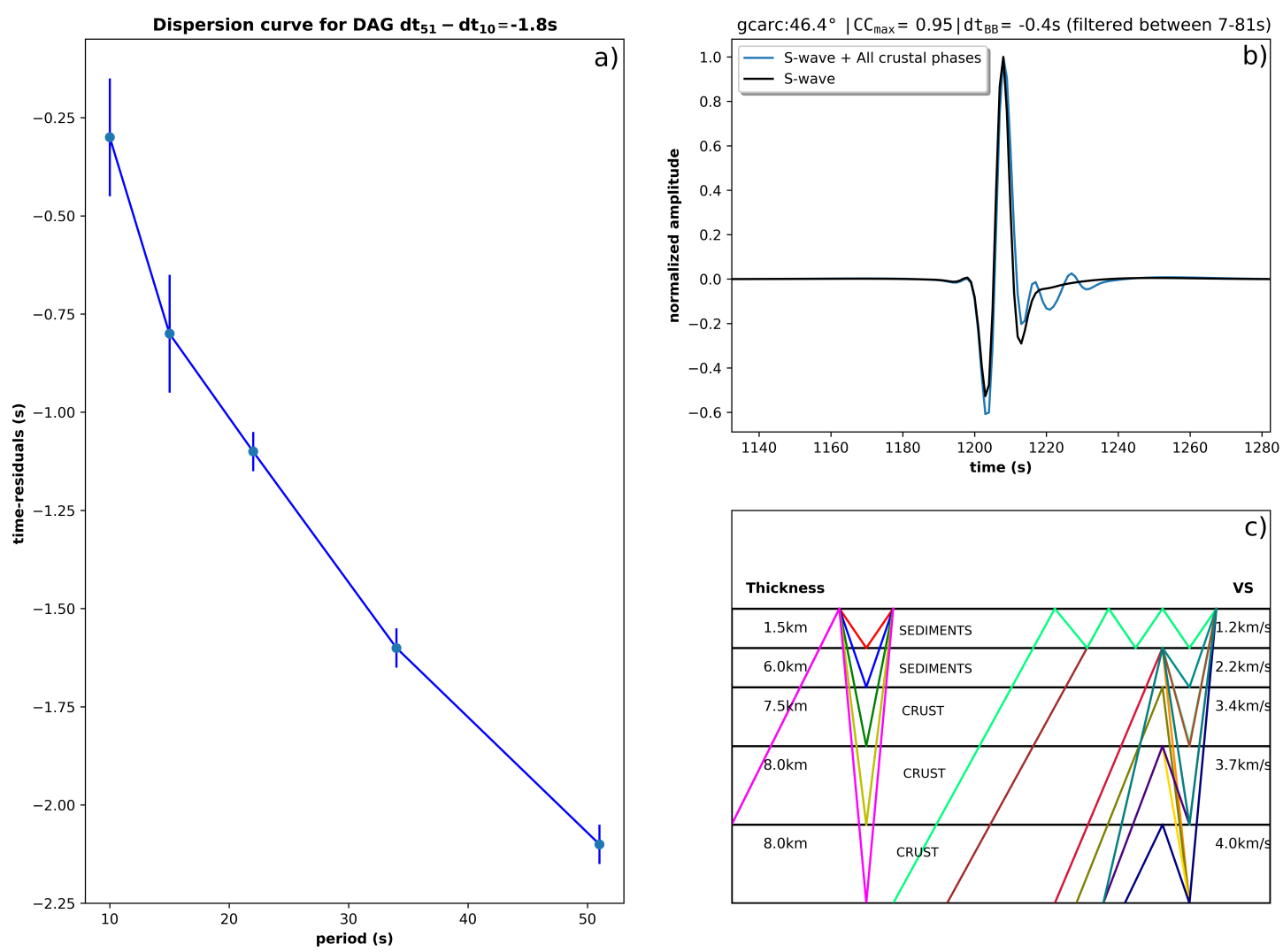

Figure 3. (a) Dispersion curve for time residuals measured at $10 \mathrm{~s}, 15 \mathrm{~s}, 22.5 \mathrm{~s}, 34 \mathrm{~s}$ and $51 \mathrm{~s}$. Error bars are estimated by using the method of Chevrot (2002). If the error is smaller than $0.1 \mathrm{~s}$ we set a minimal error. (b) Waveforms computed for a S-wave alone (black) and a S-wave + crustal phases (blue) recorded at DAG station for the same event, waveforms are filtered between 7-81 s. (c) Crustal model under the DAG station from CRUST2.0 with a schematic representation of modeled crustal phases. Crustal multiples are split into two groups for clarity. 


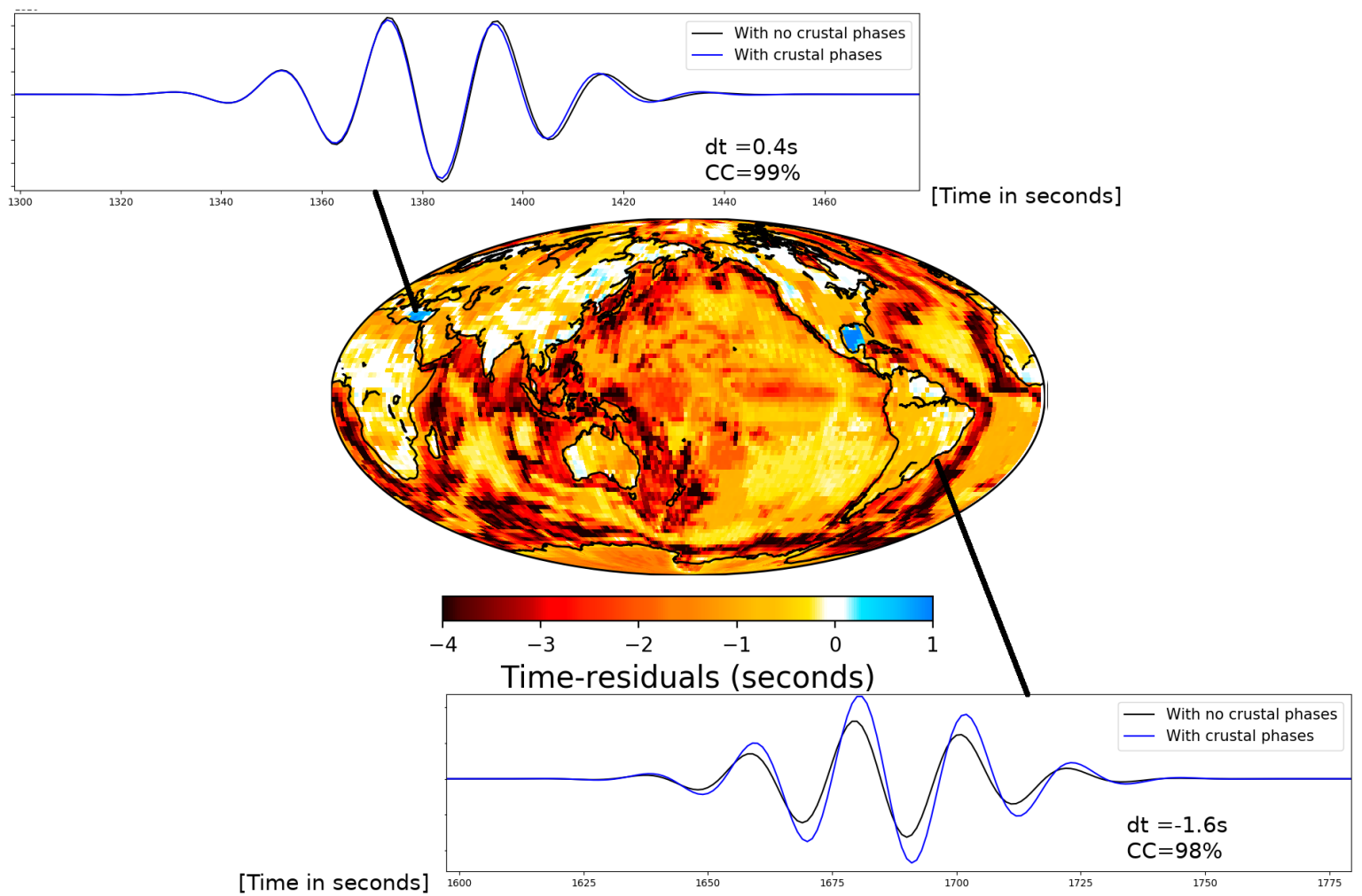

Figure 4. S-wave mean time residuals on a $1^{\circ} \times 1^{\circ}$ grid measured by cross-correlating synthetics with and without crustal phases filtered at $22.5 \mathrm{~s}$ for CRUST1.0 model ( $d t_{\text {synth }}^{\text {crust }}$ FF $(22.5 s)$ ). We modelled S, sS, ScS and $\mathrm{sScS}$ for epicentral distances from $30^{\circ}$ to $95^{\circ}$, one year of seismicity (with $5.5<M_{w}<6.5$ ) has been used to generate the whole data set. Seismograms show how the crustal phases can have an advancing or delaying effect on time residuals measured by cross-correlation. 

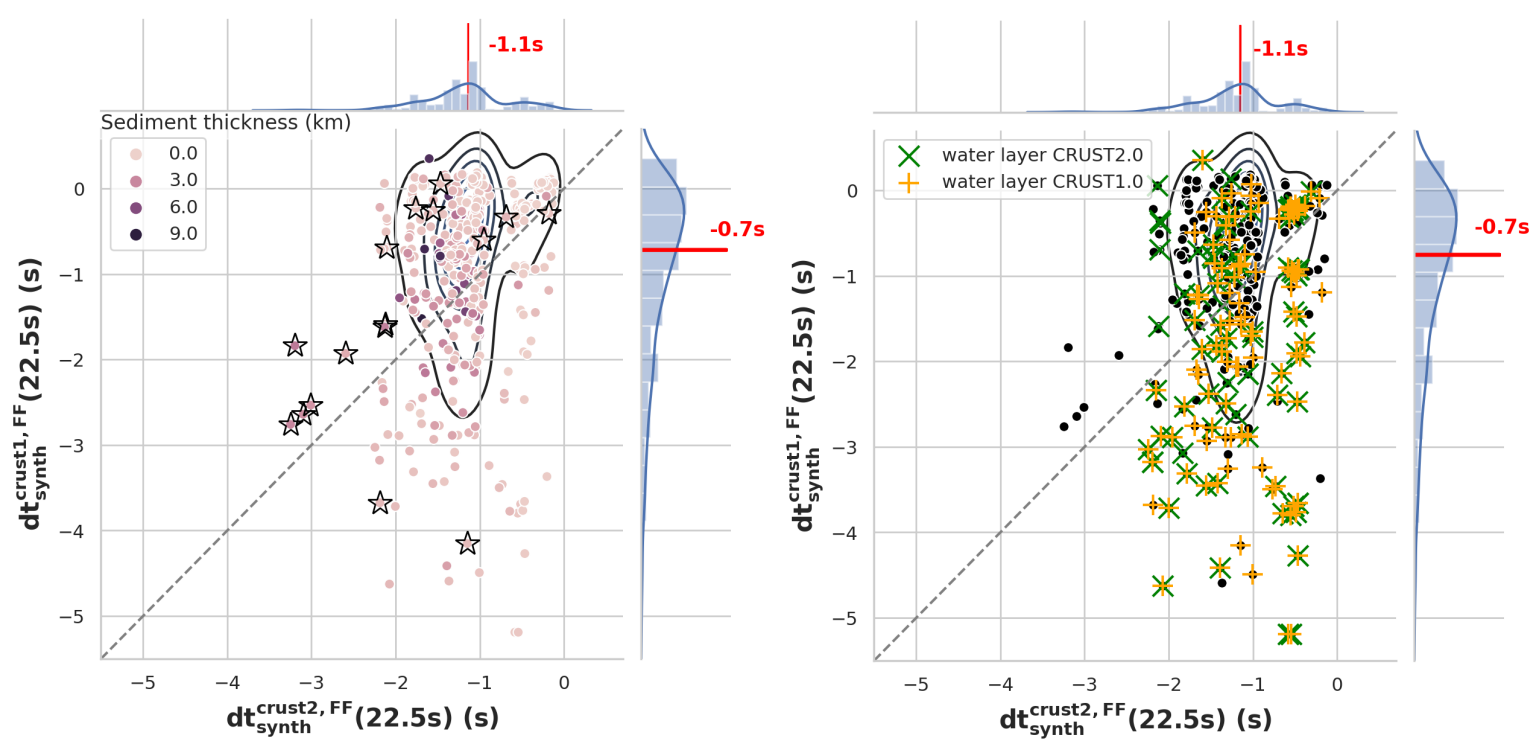

Figure 5. FF crustal corrections computed for each station with CRUST1.0 and CRUST2.0, red bars on histograms indicate the distribution medians. (Left) Color scale represents the sediment thickness under each stations in $\mathrm{km}$ (mean of CRUST1.0 and CRUST2.0), stations with ice layer are represented by black stars. (Right) Green and orange crosses indicate stations which have a water layer in CRUST2.0 and in CRUST1.0 respectively. 
a)

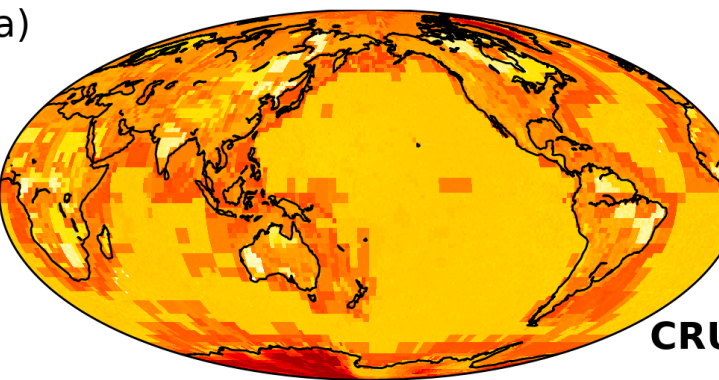

b)

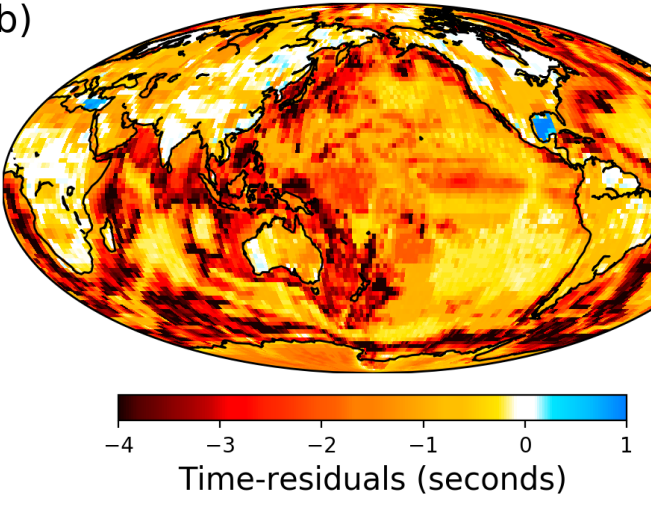

c)

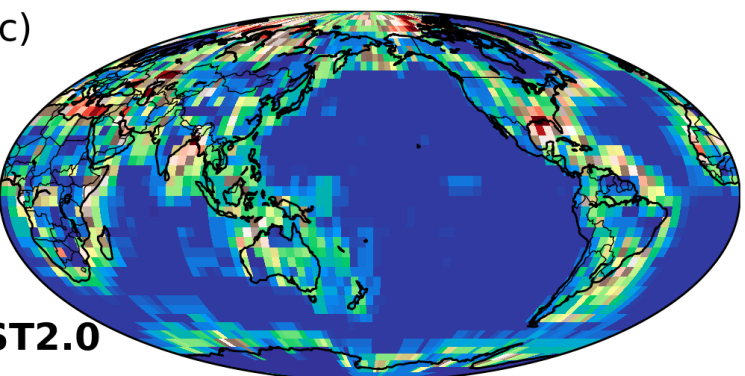

d)

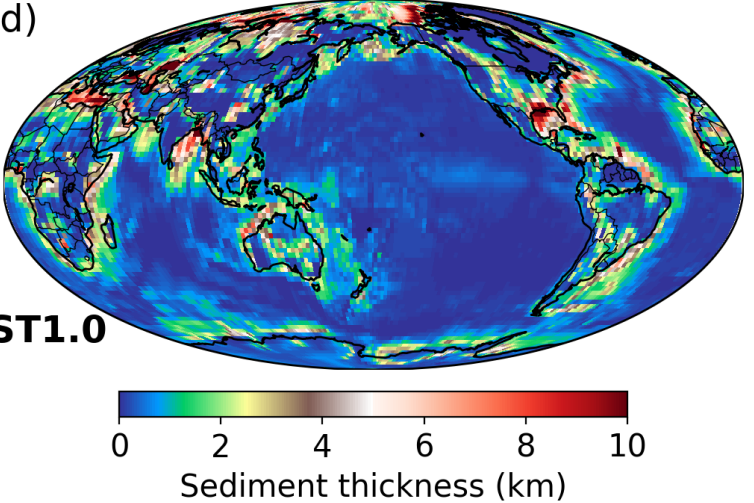

Figure 6. (a,b) S-wave mean time residuals measured by cross-correlating synthetics with and without crustal phases filtered at $22.5 \mathrm{~s}$ for (a) CRUST2.0 model $\left(d t_{\text {synth }}^{\text {crust2 FF }}(22.5 \mathrm{~s})\right.$ ) on a $2^{\circ} \times 2^{\circ}$ grid, (b) CRUST1.0 model $\left(d t_{\text {synth }}^{\text {crust1, } \mathrm{FF}}(22.5 \mathrm{~s})\right)$ on a $1^{\circ} \times 1^{\circ}$ grid. (c, d) Sediment thickness (including ice layer) for CRUST2.0 and CRUST1.0 respectively. 

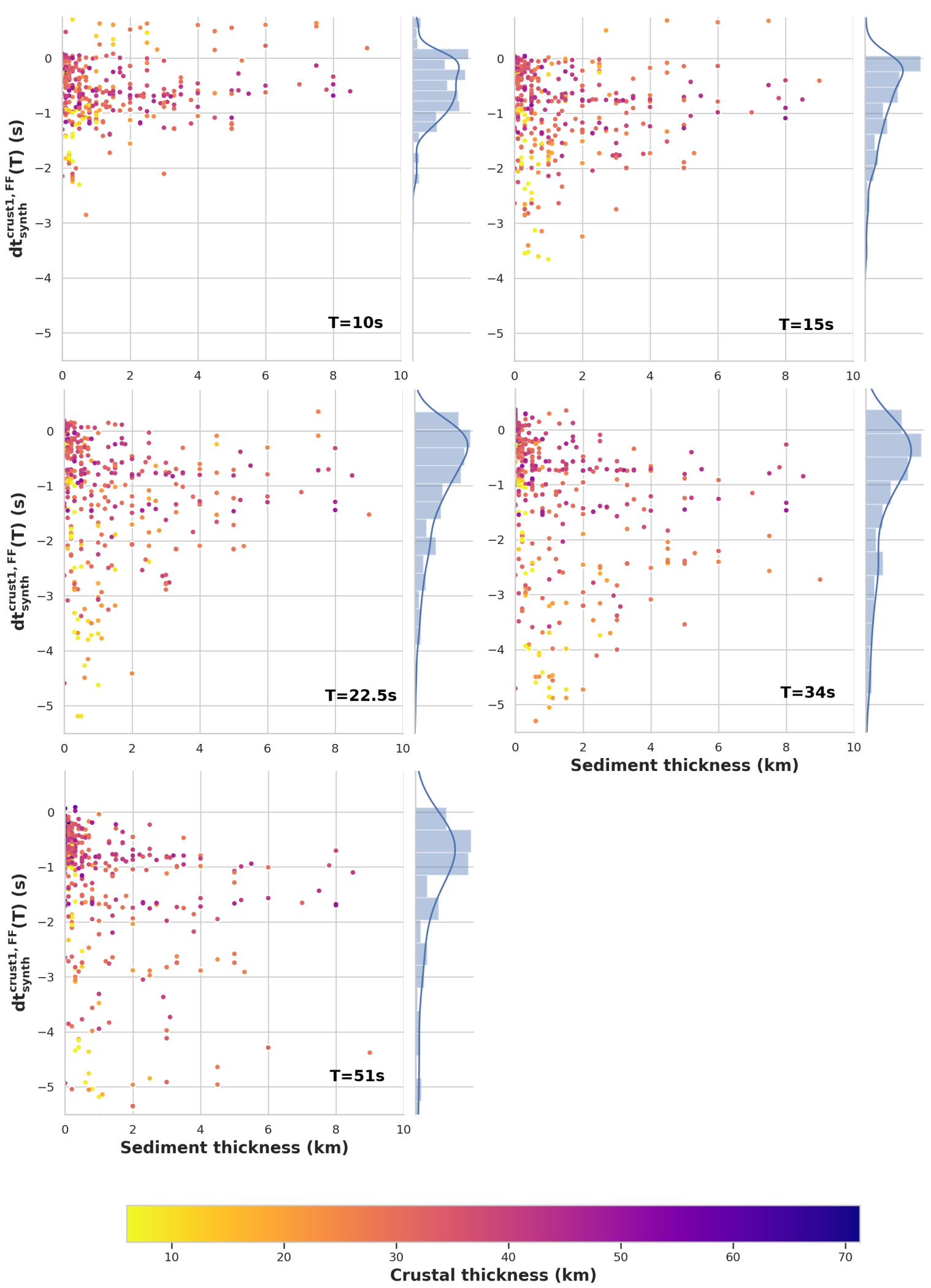

Figure 7. FF crustal corrections as a function of sediment thickness at different periods $(10 \mathrm{~s}, 15 \mathrm{~s}, 22.5 \mathrm{~s}, 34 \mathrm{~s}$, $51 \mathrm{~s}$ ) for CRUST1.0 model. Colour inside circles depends on crustal thickness (in km). Crustal thickness is the sum of sediment thickness with crystalline crustal thickness. 

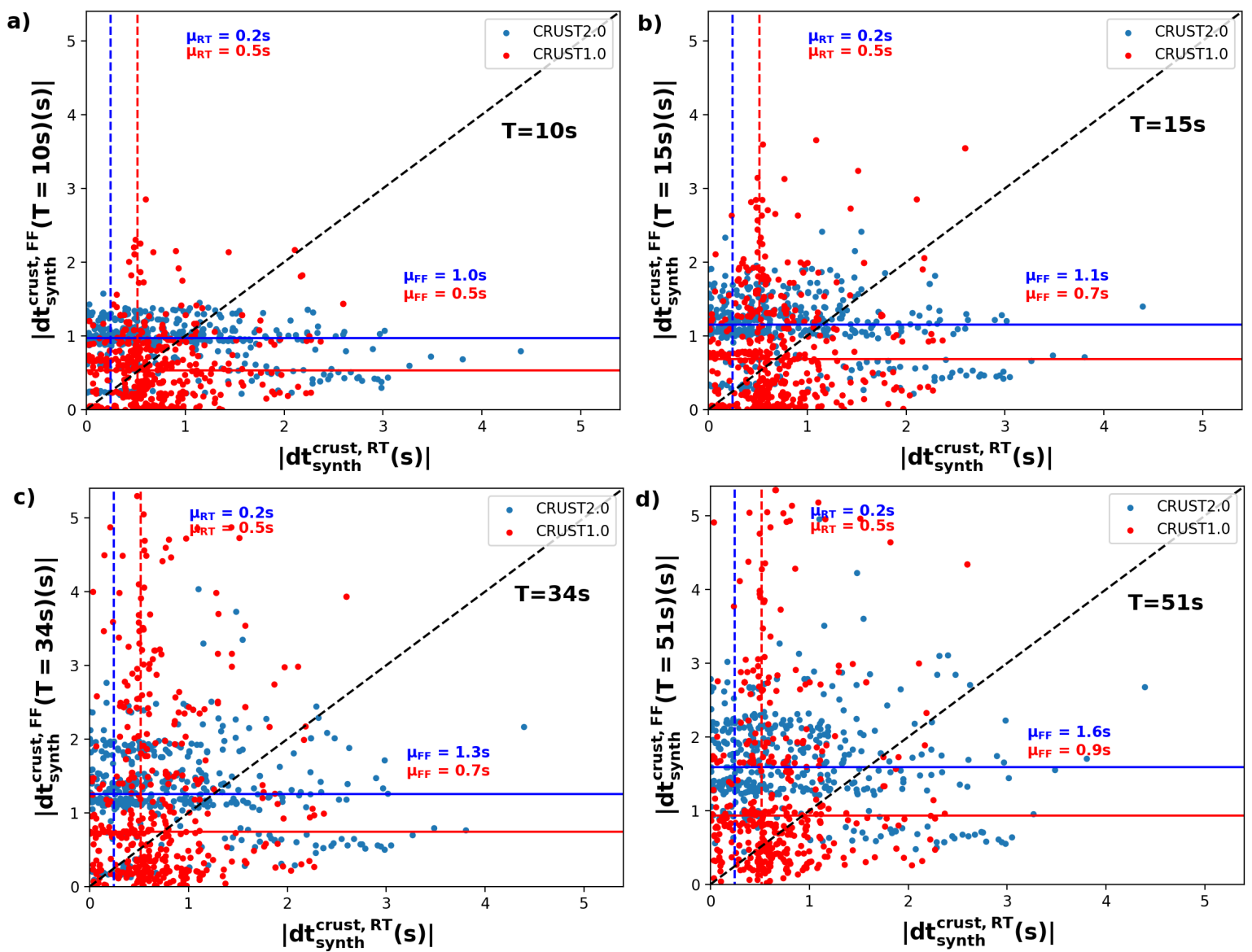

Figure 8. Synthetic FF crustal corrections versus RT crustal corrections for CRUST2.0 (blue) and CRUST1.0 (red) plotted for all the stations. FF correction computed at (a) $10 \mathrm{~s}$, (b) $15 \mathrm{~s}$, (c) $34 \mathrm{~s}$ and (d) $51 \mathrm{~s}$. Solid and dashed lines indicate medians of FF and RT crustal corrections respectively. 

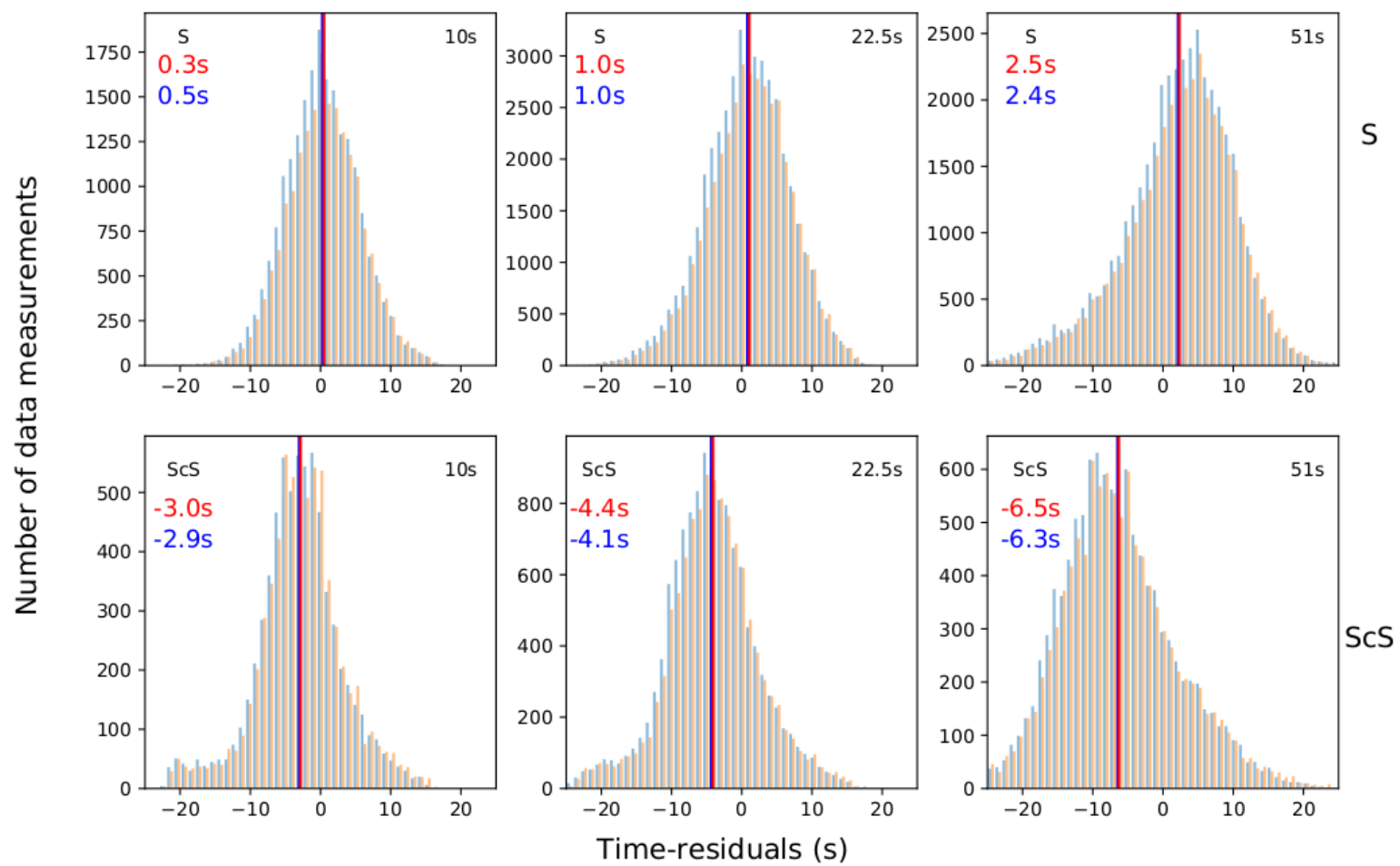

Figure 9. Histograms of time residual measured at $10 \mathrm{~s}, 22.5 \mathrm{~s}$ and $51 \mathrm{~s}$ (from left to right) for S-waves (top row) and ScS-waves (bottom row). Blue and orange histograms are measurement distributions for CRUST2.0 and CRUST1.0 respectively. Blue and red vertical lines are the means of the distributions for CRUST2.0 and CRUST1.0 respectively. The total number of successful measurements with CRUST1.0 is of 602,252 and of 628,733 with CRUST2.0, however we keep common window selection parameters for both crustal models, these parameters have been set up from tests with CRUST2.0 only. 

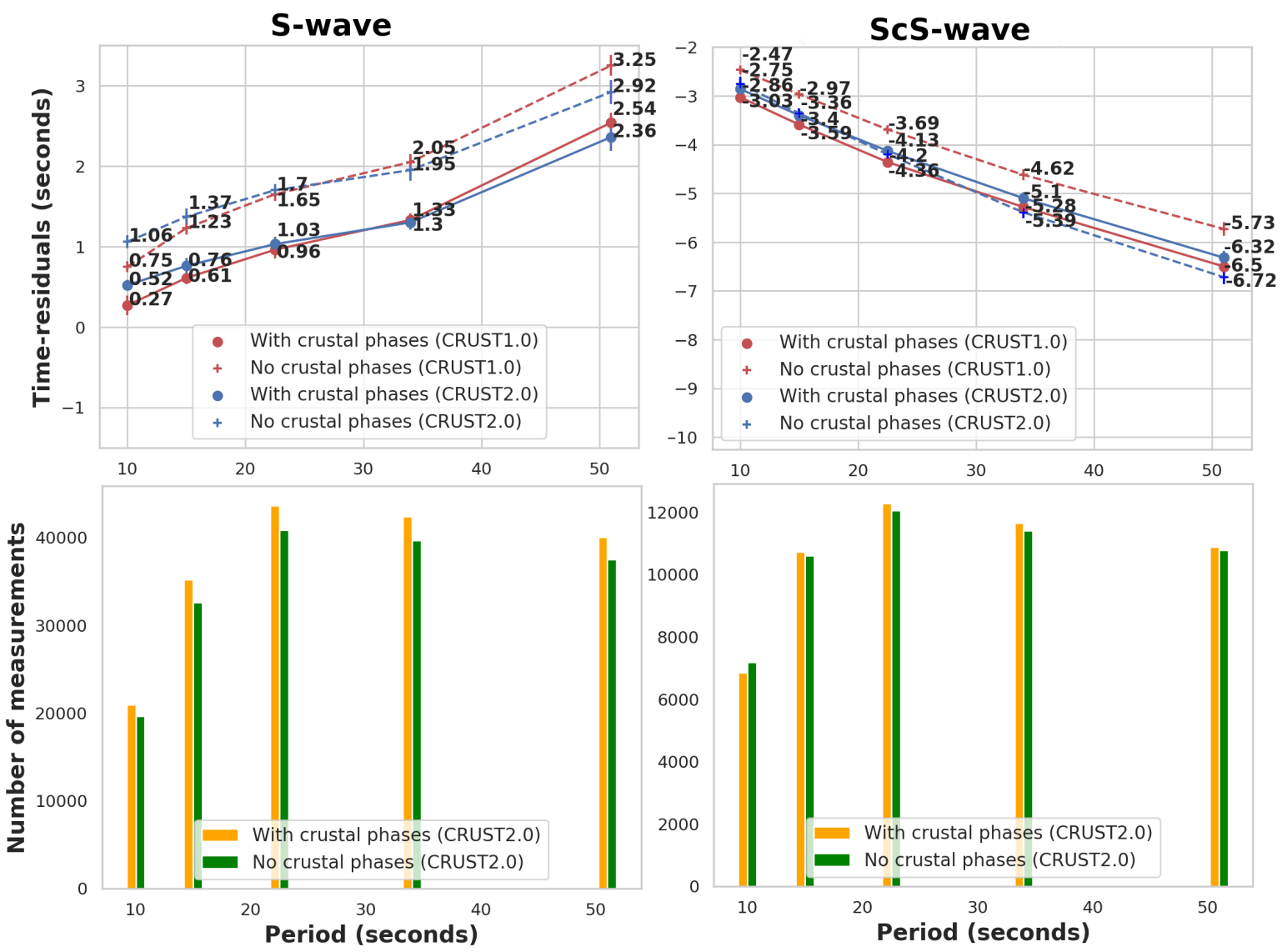

Figure 10. (Top) S-wave and ScS-wave dispersion curves for two crustal models: CRUST1.0 (red), CRUST2.0 (blue). Solid and dashed lines are measurements made with synthetics computed with or without crustal phases respectively. (bottom) S-wave and ScS-wave measurement histograms for CRUST2.0: without crustal phases (green) and with crustal phases (orange). $1-\sigma$ error bars are determined by bootstrap technique and all time residuals have been corrected for intrinsic attenuation. 

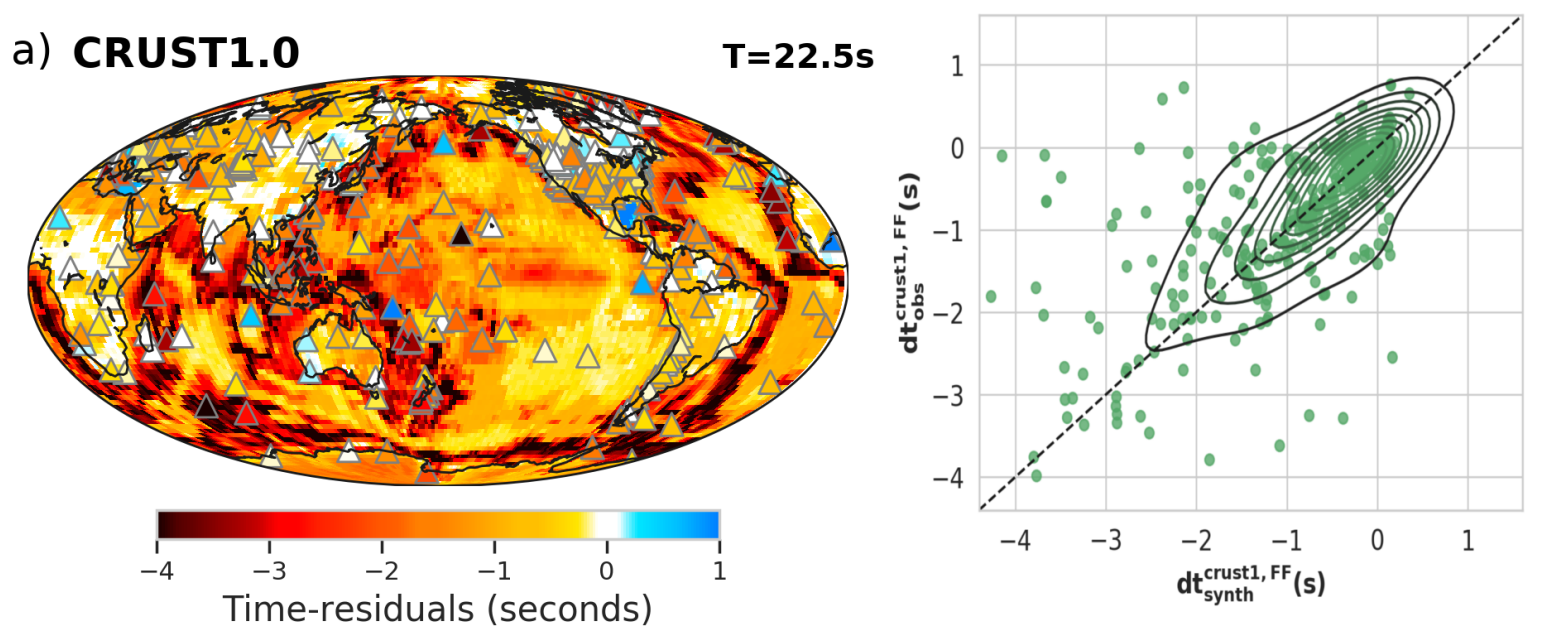

b) CRUST2.0
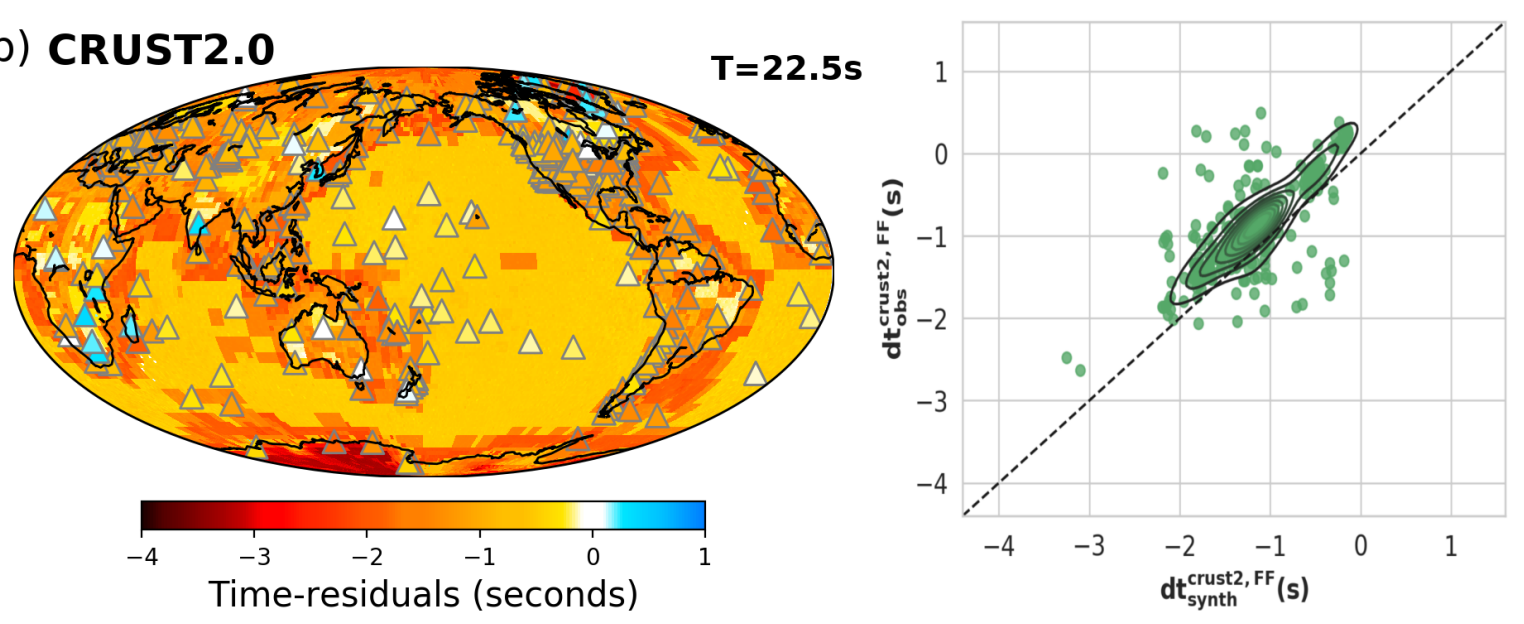

Figure 11. Global mean time residuals measured by cross-correlating synthetics with and without crustal phases filtered at $22.5 \mathrm{~s}$ over (a) $1^{\circ} \mathrm{x} 1^{\circ}$ grid for CRUST1.0 model, (b) $2^{\circ} \times 2^{\circ}$ grid for CRUST2.0 model. Colored triangles indicate the dispersive crustal effect in observed data $\left(d t_{\mathrm{obs}}^{\mathrm{CP}}(T)-d t_{\mathrm{obs}}^{\mathrm{NCP}}(T)\right.$ for $\left.\mathrm{T}=22.5 s\right)$. (Right) Comparison of observed and synthetic FF crustal corrections extracted for each station showed by triangles on the left map. 

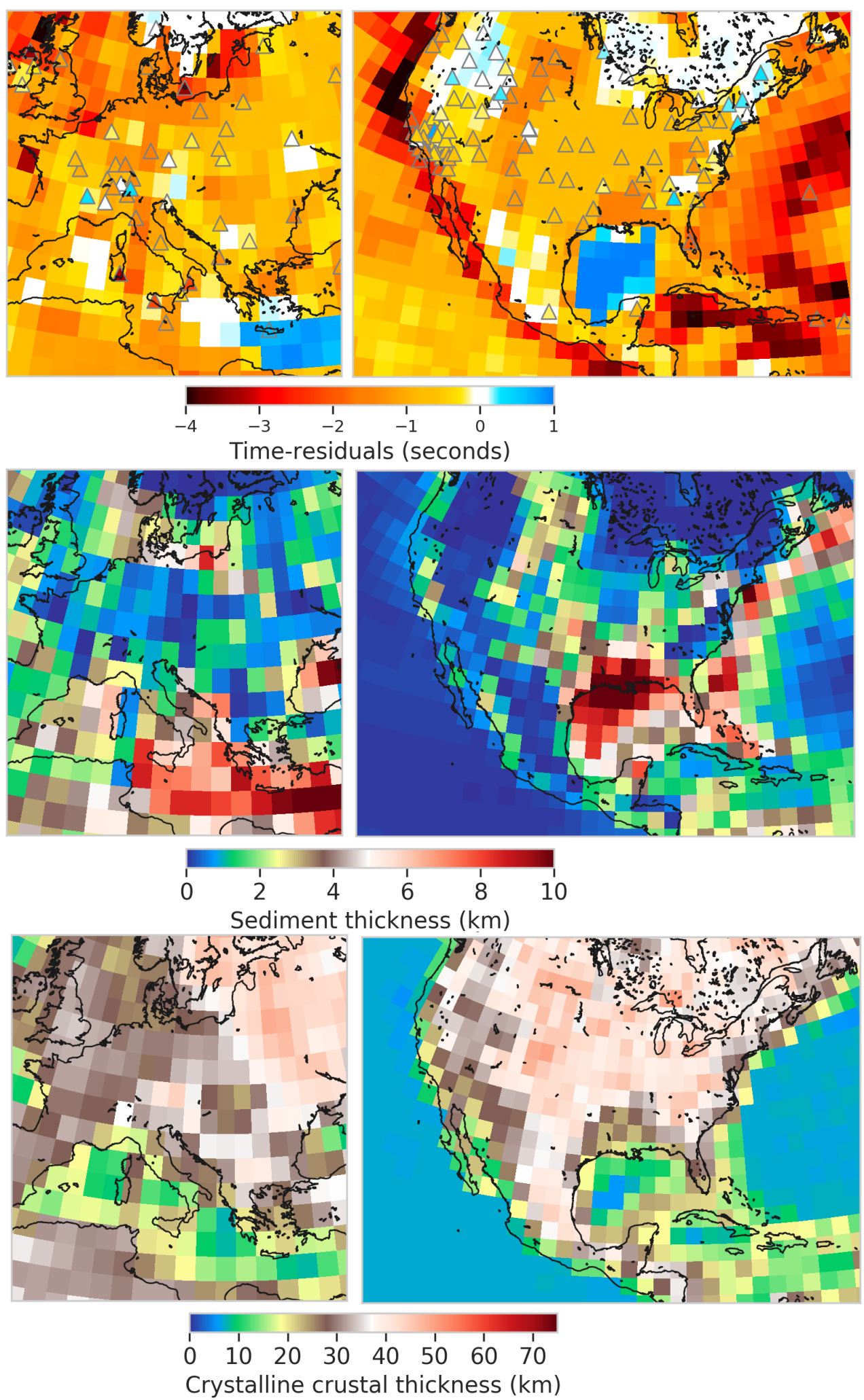

Figure 12. (Top row) Mean time-residuals measured by cross-correlating synthetics with and without crustal phases filtered at $22.5 \mathrm{~s}$ for CRUST1.0. Colored triangles indicate the dispersive crustal effect in observed data $\left(d t_{\text {obs }}^{C P}-d t_{o b s}^{N C P}\right)$. (Middle and bottom rows) Sediment and crystalline thickness maps for Europe (left) and North America (right). 
APPENDIX A: SUPPLEMENTARY FIGURES 

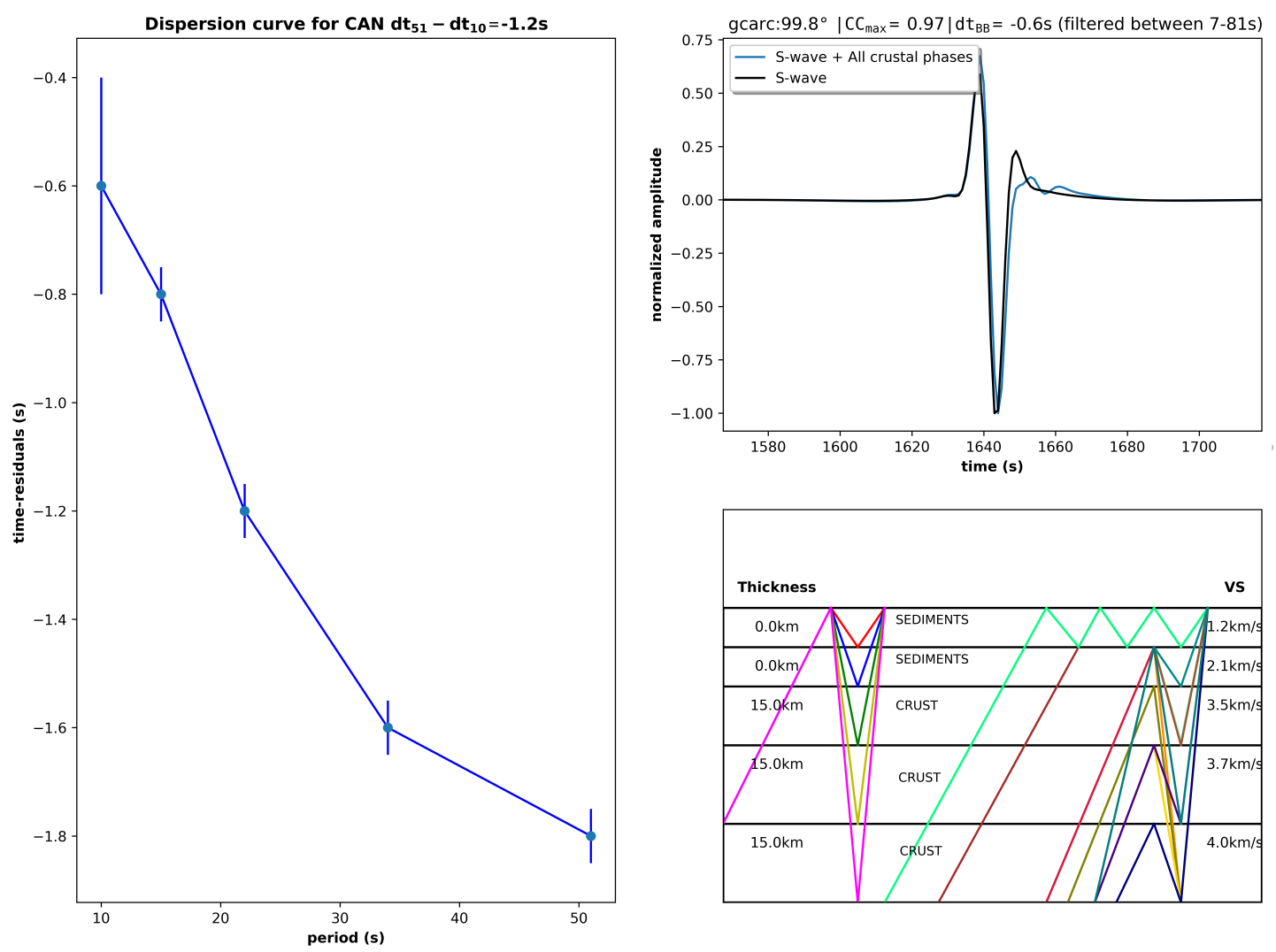

Figure A1. (a) Dispersion curve for time residuals measured at $10 \mathrm{~s}, 15 \mathrm{~s}, 22.5 \mathrm{~s}, 34 \mathrm{~s}$ and $51 \mathrm{~s}$. Error bars are estimated by using the method of Chevrot (2002). If the error is smaller than $0.1 \mathrm{~s}$ we set a minimal error. (b) Waveforms are computed with a S-wave alone (black) and a S-wave + crustal phases (blue) recorded at station CAN, waveforms are filtered between 7-81 s. (c) Crustal model under the station from CRUST2.0 with a schematic representation of modeled crustal phases. In this case crustal phases drawn in sediment layers are not modelled in our synthetics, only reflections in the last three layers are included. 


\section{SS-wave}

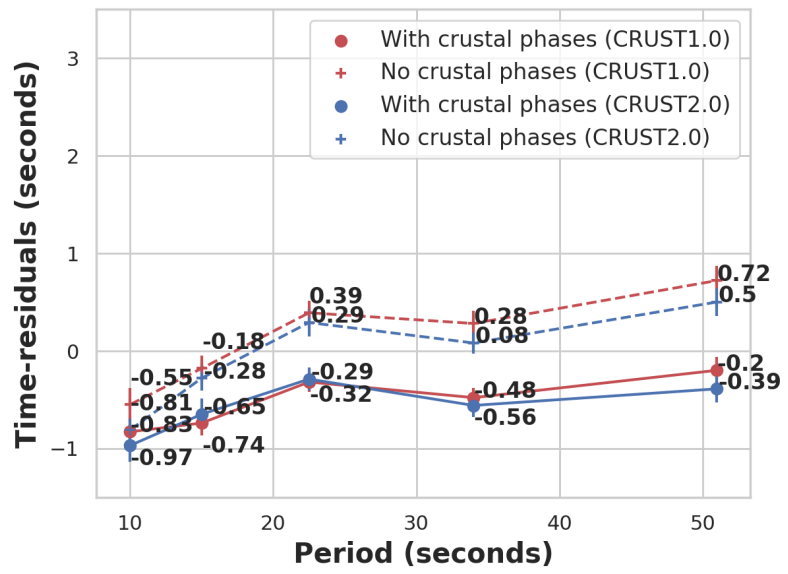

\section{ScS $_{2}$-wave}

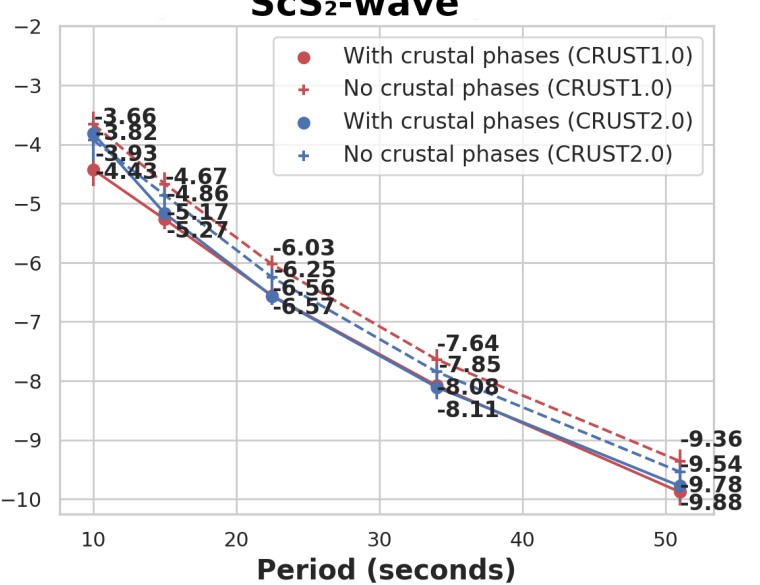

Figure A2. SS and $\mathrm{ScS}_{2}$-waves dispersion curves for two crustal models: CRUST1.0 (red), CRUST2.0 (blue).

Solid and dashed lines are measurements made with synthetics computing with or without crustal phases respectively. SS has same y-axis as for $\mathrm{S}$ waves and $\mathrm{ScS}_{2}$ has same y-axis as for $\mathrm{ScS}$ waves in Figure 10. 

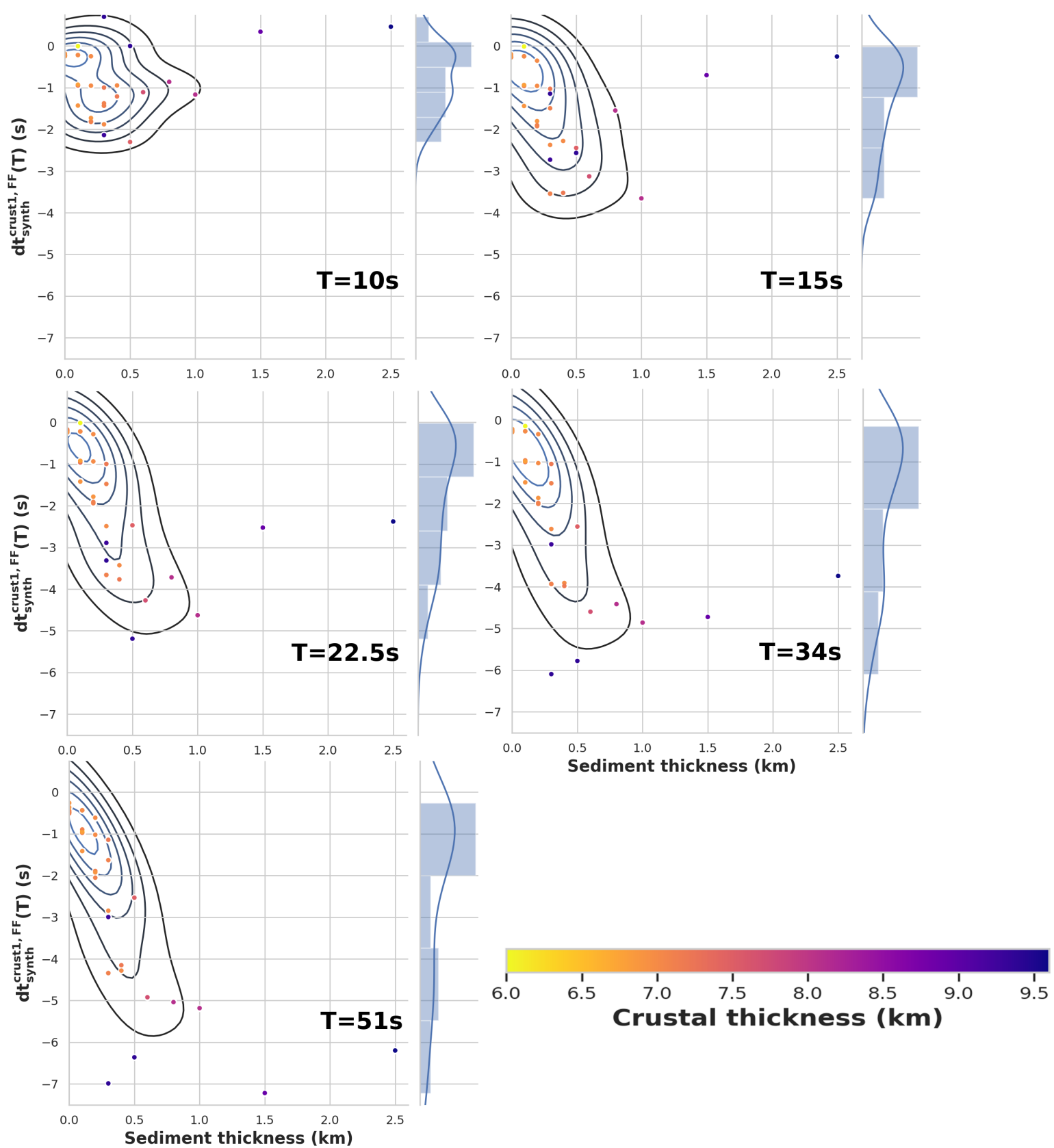

Figure A3. FF crustal corrections as function of sediment thickness at different periods $(10 \mathrm{~s}, 15 \mathrm{~s}, 22.5 \mathrm{~s}, 34 \mathrm{~s}$, $51 \mathrm{~s}$ ) for CRUST1.0. Colour inside circles depends on crustal thickness (in km). Crustal thickness is the sum of sediment and crystalline crustal thicknesses. We plot here only stations with thin crustal thicknesses $(<12 \mathrm{~km})$, which are stations for which CRUST1.0 gives an oceanic crust. 

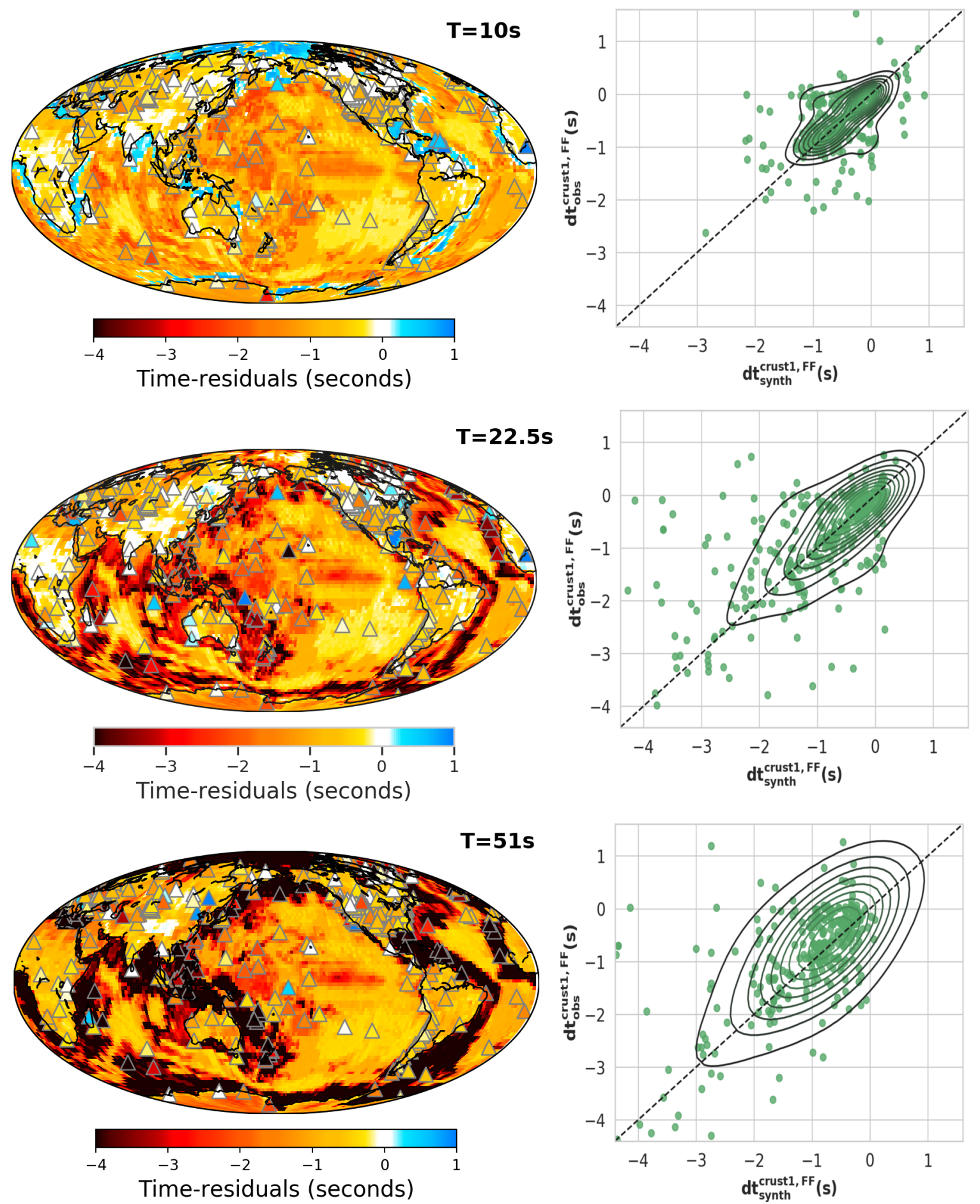

Figure A4. (Left) Global mean time residuals measured by cross-correlating synthetics with and without crustal phases over $1^{\circ} \mathrm{x} 1^{\circ}$ grid filtered at (top row) 10s, (middle row) $22.5 \mathrm{~s}$ and (bottow row) 51s for CRUST1.0 model. Colored triangles indicate the dispersive crustal effect in observed data $\left(d t_{\mathrm{obs}}^{\mathrm{CP}}(T)-d t_{\mathrm{obs}}^{\mathrm{NCP}}(T)\right)$. (Right) Comparison of observed and synthetic FF crustal corrections extracted for all the stations shown by triangles on left maps. 

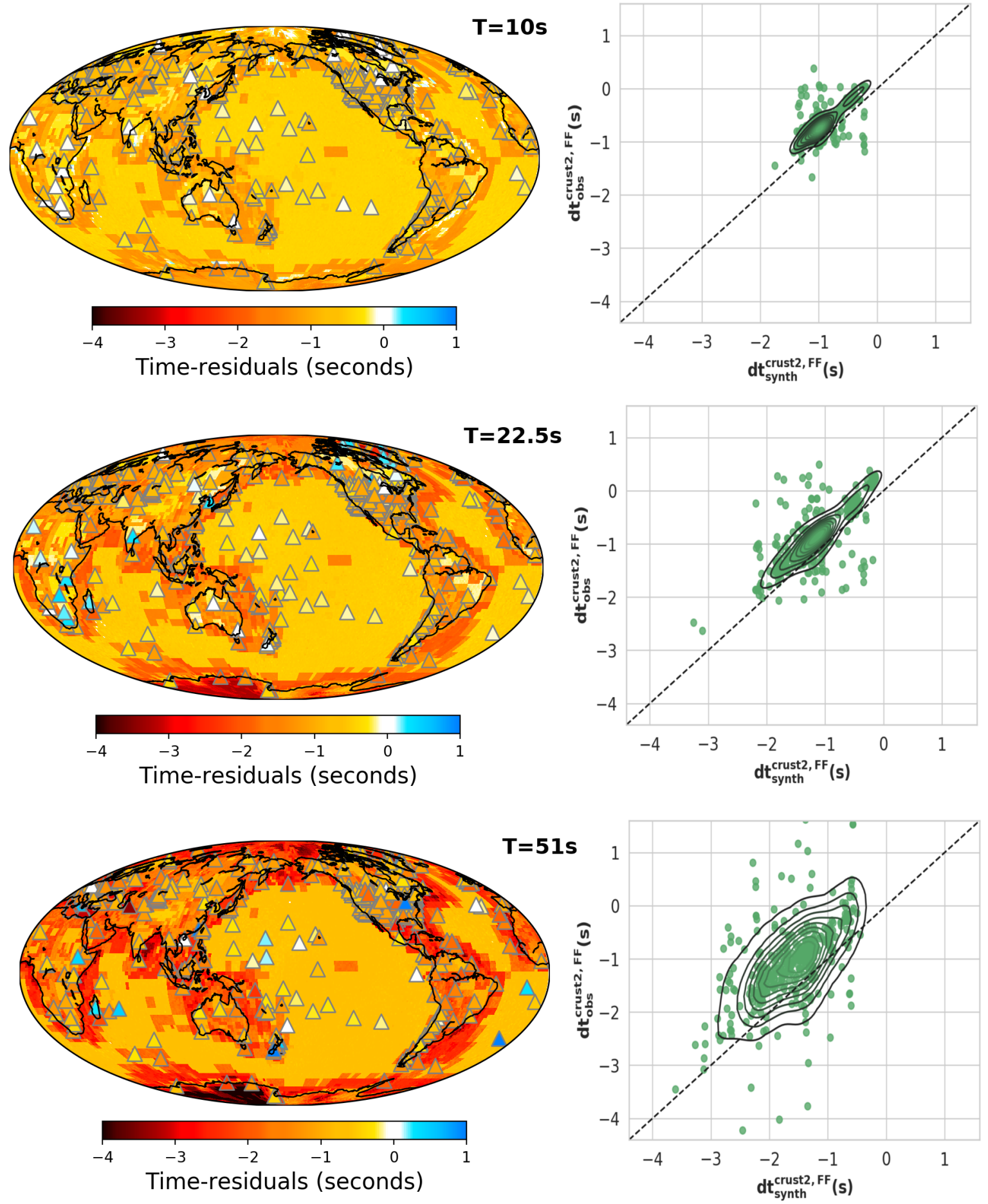

Figure A5. (Left) Global mean time residuals measured by cross-correlating synthetics with and without crustal phases over $2^{\circ} \times 2^{\circ}$ grid filtered at (top row) $10 \mathrm{~s}$, (middle row) $22.5 \mathrm{~s}$ and (bottow row) $51 \mathrm{~s}$ for CRUST2.0 model. Colored triangles indicate the dispersive crustal effect in observed data $\left(d t_{\mathrm{obs}}^{\mathrm{CP}}(T)-d t_{\mathrm{obs}}^{\mathrm{NCP}}(T)\right)$. (Right) Comparison of observed and synthetic FF crustal corrections extracted for all the stations shown by triangles on left maps. 

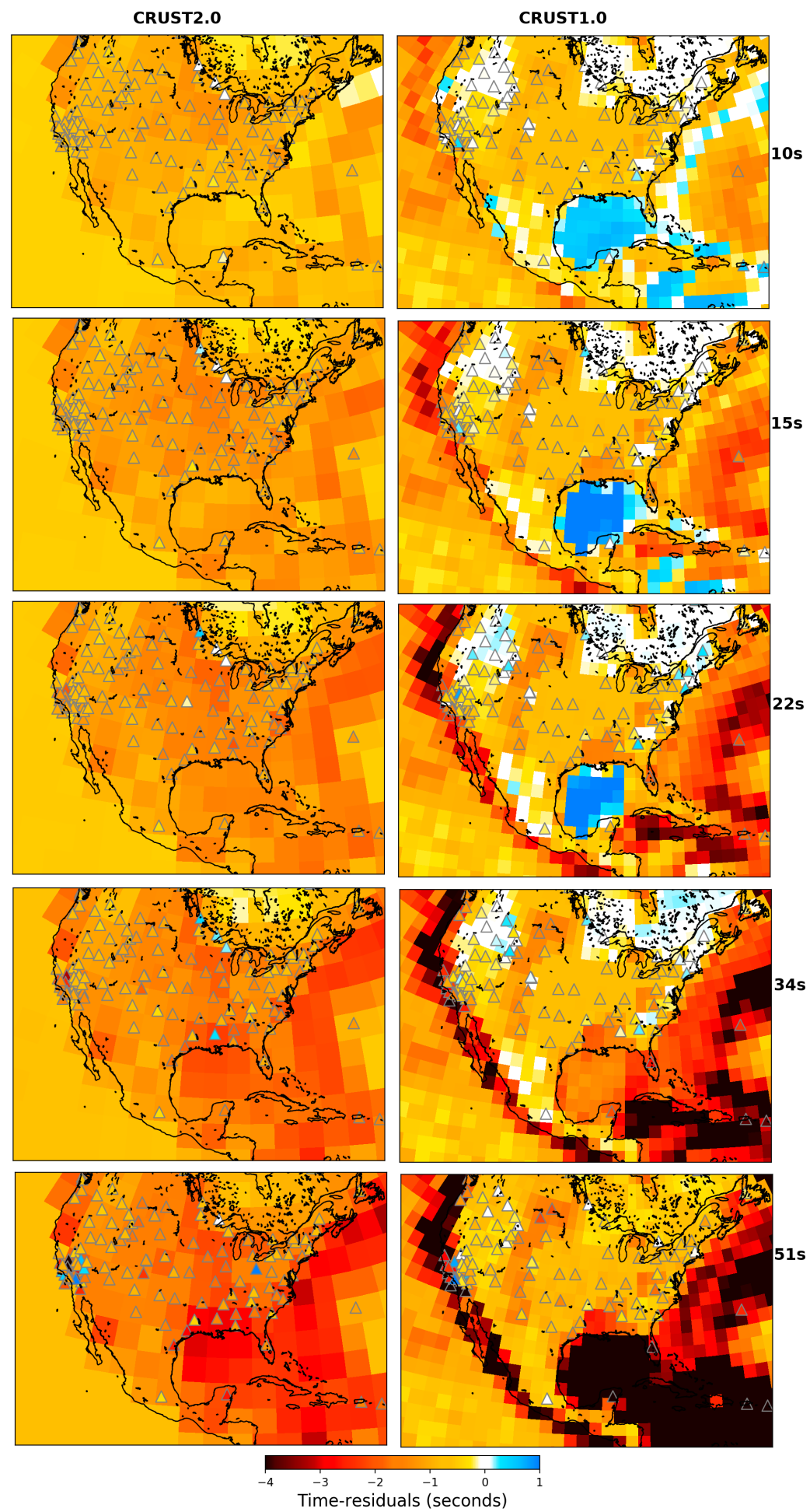

Figure A6. S-wave mean time residuals measured by cross-correlating synthetics with and without crustal phases for (left column) CRUST2.0 model on a $2^{\circ} \times 2^{\circ}$ grid (right column) CRUST1.0 model on a $1^{\circ} \times 1^{\circ}$ grid filtered at $(10 \mathrm{~s}, 15 \mathrm{~s}, 22.5 \mathrm{~s}, 34 \mathrm{~s}, 51 \mathrm{~s})$. We modelled S, sS, ScS and sScS for epicentral distances over $30^{\circ}$ to $95^{\circ}$, one year of seismicity (with $5.5<M_{w}<6.5$ ) is used to generate the data set. Only stations with at least 5 measurements are plotted, which explains the difference in number of stations between the two crustal models and the different frequencies. 